\title{
Looking Back on 35 Years of Industrial Catalysis
}

\author{
Hans-Ulrich Blaser* \\ KGF-SCS Distinguished Industrial Investigator Award 2014 \\ Dedicated to Professor Albert Eschenmoser on the occasion of his $90^{\text {th }}$ birthday.
}

\begin{abstract}
This article is an account of my 35 years in the Basel Chemical Industry, starting in 1976 as a young research chemist in the Central Research Laboratories of Ciba-Geigy until my retirement as Chief Scientific Officer of Solvias in 2011. In the first section, important aspects of industrial research are commented from my personal point of view with particular emphasis on the importance of team work and the situation of catalysis in the (Swiss) fine chemicals industry. In the next sections, the three most important areas of catalytic research are described where my colleagues and I could not only solve specific Ciba-Geigy / Novartis / Solvias problems, but also developed industrially relevant, generally applicable catalytic methodologies and contributed to the understanding of these complex catalytic transformations: i) Catalytic $\mathrm{C}-\mathrm{C}$ and $\mathrm{C}-\mathrm{N}$ coupling catalysis where we developed highly efficient catalysts for the Heck, Suzuki, Buchwald-Hartwig reactions; ii) Hydrogenations using modified heterogeneous catalysts, especially the chemoselective reduction of functionalized nitro arenes and the enantioselective hydrogenation of substituted ketones using Pt catalysts modified with chinchona alkaloids where mechanistic studies led to a working understanding of this fascinating reaction; iii) Enantioselective homogeneous hydrogenation and chiral ligands. The process development for the production of (S)-metolachlor, an important herbicide via an iridium-Josiphos catalyzed $\mathrm{C}=\mathrm{N}$ hydrogenation is described in some detail, followed by a brief description how the Solvias Ligand Portfolio was developed.
\end{abstract}

Keywords: Heterogeneous catalysis · Homogeneous catalysis · Industrial catalysis · (S)-Metolachlor

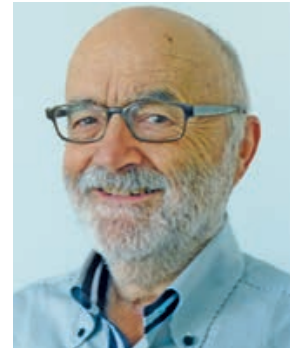

Hans-Ulrich Blaser carried out his doctoral research with Albert Eschenmoser at the Federal Institute of Technology (ETH) Zürich, where he received the PhD degree in 1971. Between 1971 and 1975 he held postdoctoral positions at the University of Chicago (J. Halpern), Harvard University (J. A. Osborn), and Monsanto (Zurich). During 20 years at Ciba-Geigy (1976-1996) he gained practical experience in $R \& D$ in the fine chemicals and pharmaceutical industry, which continued at Novartis (1996-1999) and at Solvias where he was chief technology officer until 2011 and scientific advisor until

${ }^{*}$ Correspondence: Dr. H.-U. Blase

Furglerstrasse 10

$\mathrm{CH}-9000$ St. Gallen

(Formerly Ciba-Geigy, Novartis and Solvias)

E-mail: blaserhu@gmail.com spring 2012. From 2004 to 2012 he was research councilor of the Swiss National Science Foundation where he chaired the Mathematics, Natural and Engineering Sciences section for the last two years. He is now retired but keeps a strong interest in all aspects of enantioselective catalysis with special emphasis on industrial applications. During his industrial carrier he developed and implemented numerous catalytic routes for agrochemicals, pharmaceuticals and fine chemicals both as project leader and section head. He and his team have received several awards for their contributions to industrial catalysis in general and enantioselective catalysis in particular, notably the Sandmeyer Award of the Swiss Chemical Society in 1999, the Horst Pracejus Prize of the German Chemical Society (2009) and the Paul Rylander Award of the Organic Reaction Catalysis Society (2010).

\section{Introduction: Catalysis in the Fine Chemicals Industry - A Personal View}

Traditionally, fine and specialty chemicals have been produced using predominantly non-catalytic organic synthesis.
This is in strong contrast to the production of bulk chemicals, which relies heavily on catalysis. The difference can be explained on the one hand by the higher complexity of fine chemicals which makes catalysis more demanding and on the other hand by the fact that process chemists are usually more familiar with sophisticated organic synthesis. Nevertheless, the application of selected catalytic methods has increased in recent years in part because both production costs and waste minimization are of growing importance, even for high value pharmaceuticals, and also due to the new catalytic methods developed in academic laboratories which are now slowly finding their way into industrial laboratories. ${ }^{[1]}$

The predominance of non-catalytic reactions was also true for Ciba-Geigy when I joined their Central Research Laboratories in 1976, even though it already had a very well-functioning service hydrogenation laboratory as well as several large-scale hydrogenation processes in operation. In addition, first efforts were already ongoing to study homogeneous catalytic $\mathrm{C}-\mathrm{C}$ forming reactions, especially $\mathrm{Ni}$-catalyzed reactions of butadiene with various $\mathrm{C}=\mathrm{N}$ systems. ${ }^{[2]}$ The goal of this endeavor was the synthesis of novel amines not readily available through classical organic synthe- 
sis and to test these molecules for various applications of interest to the producing divisions of Ciba-Geigy.

Even though my first project was also in this area, I was more interested in catalytic methods which could be applied to the synthesis of more complex molecules and - even more important - which were viable for industrial applications. That was one of the reasons that around 1978 I joined the section 'Katalyse/Synthesedienste' headed by Rolf Bader who asked me to build up a research group for catalytic methodologies. My colleagues and I were very lucky that over the next 20 years all levels of Ciba-Geigy's management strongly supported our ever growing catalytic efforts to develop catalytic methods with industrial potential (Table 1)..$^{[3]}$

Very early on, we decided to concentrate our research on transformations and catalyst types with the greatest potential for the needs of a specialty chemicals company with high flexibility for constructing important structural motifs and for the transformation of functional groups: Chemoselective hydrogenation using (modified) heterogeneous catalysts; homogeneous and heterogeneous enantioselective hydrogenation, and homogeneous coupling reactions. These methodologies share the following properties: They have a broad scope to make important structural moieties; many catalysts are (relatively) easy to apply and are now commercially available and, last but not least, process chemists 'believe' more and more in the potential of these technology (success breeds success). During the years as part of the Central Research Laboratories, we were able to build a substantial basis of important $R \& D$ results in all three areas and also implemented a number of significant production processes. After the spin-off into Solvias in 1999, these results formed the basis for services offered in the area of catalysis. ${ }^{[4]}$

In the following sections, a brief outline will be given how the three fields developed and two case studies will be discussed in some detail in order to illustrate our approach to developing catalytic methodology: The investigation of cinchonamodified platinum catalysts for the asymmetric hydrogenation of activated ketones and the enantioselective hydrogenation of $\mathrm{C}=\mathrm{N}$ bonds with homogeneous $\mathrm{Ir}-$ diphosphine complexes allowing the chiral switch of the metolachlor herbicide. In both cases, we not only could solve a specific CibaGeigy problem, but also developed generally applicable methodologies and contributed to the understanding of these complex catalytic transformations.

Before starting the chemical discussion let me make some remarks about how the situation of a chemist working in the

Table 1. Catalysis in Ciba-Geigy, Novartis and Solvias

1940s Geigy opens a 'Hydrierlabor' for preparative services.

1960s Process development; first hydrogenation processes implemented.

1970s Central Research Laboratories are founded. Ni-catalyzed reactions of butadiene.

1976 HUB: Start of R\&D in homogeneous C-C coupling catalysis and chemoselective heterogeneous hydrogenation.

1980s R\&D in homogeneous and heterogeneous enantioselective hydrogenation.

1990s Chiral ligand research; $(S)$-metolachlor process implemented.

1996 Ciba-Geigy + Sandoz $=$ Novartis: Chemical research no longer first priority.

1999 Solvias spun-off as independent company; technology and customer service provider; chiral ligand supplier (R\&D focus restricted to chiral ligands).

(Swiss) chemical industry has developed in the 35 years since 1976 when I began working for Ciba-Geigy. When one decided to work as a research chemist for one of the Big Three in Basel (Ciba-Geigy, Roche or Sandoz), it was with the implicit understanding that this was probably for 'life'. It was almost impossible to change to one of the other companies and there were of course almost unlimited opportunities for career development within the company (at least in theory). Many things have changed since then. Except for Roche, the companies have changed names (and logos), have merged and spun-off so that the chemical landscape in Basel is very different now. My personal situation has changed accordingly. I started out at Ciba-Geigy, which changed its name to Ciba (maybe because Geigy was difficult to pronounce in English?) and obtained a new colorful logo (see Fig. 1). Then Ciba merged with Sandoz to Novartis (with an even more colorful $\log$ ) and for the last part of my career I was part of Solvias (with the prettiest logo!). Interestingly, during most of this time I worked in the same building with more or less the same team and the same tasks! So in the end, I indeed did not actively change companies during all these years but the companies changed - quite unexpected when it happened but by now a very common situation.

Even more than in academia, success in industrial research relies very heavily on a team effort and the contributions of specialists with different know how and expertise. In all my years at Ciba-Geigy, Novartis and Solvias I was very lucky that I could rely on excellent collaborators. Without their efforts and dedication none of the results obtained in my 35 years of industrial catalysis would have been possible. While I will describe the contributions of most of them in the context of the chemical discussions below, I would like to mention some with special relevance to my projects (see Fig. 2): Rolf Bader, Peter Baumeister, Urs Siegrist and Heinz Steiner, my colleagues for over 20 years in the management team of the Katalyse/Synthesedienst section; Felix Spindler, Benoît Pugin with whom I started the project on homogeneous catalysis which culminated in the metolachlor success; Daniel Monti, Marc Garland and especially Martin Studer who made vital contributions in the project with modified heterogeneous catalysts and finally the late Hans-Peter Jalett who worked in both areas as an exceptionally talented chief technician. In addition I am indebted to Antonio Togni and Andreas Pfaltz for scientific advice as well as their contributions to the various projects and last but not least to Hans-Jochen Dannappel who very skillfully wrote the many patents to protect our intellectual property rights.

\section{Palladium-catalyzed Coupling Catalysis (Heck, Suzuki, Buchwald- Hartwig Reactions)}

Around 1978 I started to investigate $\mathrm{Pd}$-catalyzed $\mathrm{C}-\mathrm{C}$ coupling reactions. This was triggered by the fascinating reaction of olefins with aryl iodides and bromides published almost simultaneously by Mizoroki and Heck with the potential to prepare substituted styrene and stilbene derivatives, interesting structures for brighteners. The original Heck catalysts had two drawbacks: First, good results were only obtained with (relatively expensive) aryl iodides or activated bromides and the required catalyst loadings of $1-2 \%$ were too

\section{CIBA-GeIGY G[ibo] (l) Novartis solvias}

Fig. 1. Names and logos of companies I worked for over the years. 


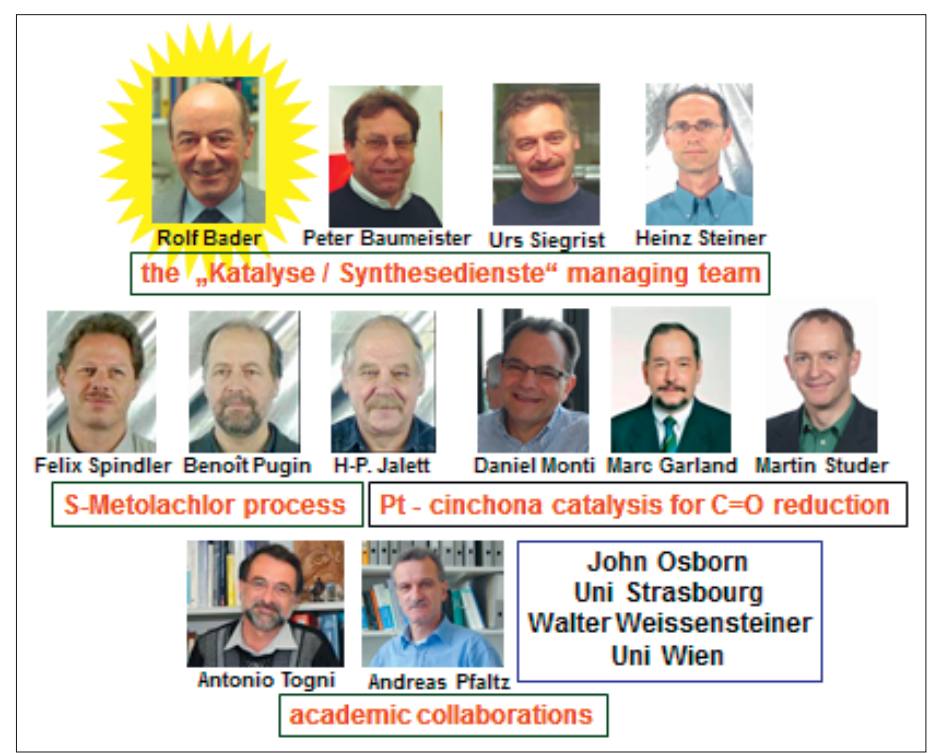

Fig. 2. Industrial research is a team effort.

high for most industrial applications. In the following years, a sizeable R\&D program (see Table 2) was launched (in part to find answers to these problems) which resulted in some quite spectacular successes..$^{[5]}$

Since I was personally involved in only a few of these projects I will restrict my discussion to some early investigations which were conducted in collaboration with Alwyn Spencer whom I met earlier in the Monsanto research laboratories in Zurich and who moved to Ciba-Geigy after these were closed down.

In order to improve the catalytic activity of the Heck system, we systematically studied the effect of the reaction parameters, particularly of the ligand, the base and the solvent for the reaction of several para-substituted aryl bromides. It was found that the combination of amide solvents with carboxylates as base allowed the realization of $>100,000$ turnovers; for many years the most effective Heck reaction known (see Fig. 3). ${ }^{[6]}$ Indeed, similar solvent-base combinations are now rouFor $p$-nitro bromobenzene, a record of 134,000 turnovers was obtained, albeit at only $67 \%$ conversion. The report by Heck that $\mathrm{P}(o-\mathrm{Tol})_{3}$ was slightly more effective than $\mathrm{PPh}_{3}$ was confirmed but it was also shown that up to 7800 turnovers could be obtained without phosphine ligand. This was surprising at the time because it was thought that ligand-less catalysts worked only for aryl iodides.

We also tried to extend the reaction to aryl chlorides but with only limited success. Due to the low reactivity of even the most activated aryl chlorides, temperatures of $160{ }^{\circ} \mathrm{C}$ were necessary and under these conditions, the catalyst was not stable and inactive Pd metal precipitated. Nevertheless, methyl $p$-chlorobenzoate reacted with methyl acrylate in about $50 \%$ yield to the corresponding aryl acrylate. C-N coupling reactions mides. tinely used to carry out Heck reactions.
Since aryl iodides and bromides are sometimes quite expensive and/or not easily accessible, we started to look for alternative substrates. Since many substi- tuted aryl acids are easily accessible and usually cheaper than aryl bromides we examined the corresponding aroyl chlorides as alternative substrates for the Heck reaction. The big question was whether the postulated $\mathrm{Ar}-\mathrm{CO}-\mathrm{Pd}-\mathrm{Cl}$ intermediate would react directly with the olefin to give the unsaturated ketone or whether the $\mathrm{CO}$ was ejected fast enough. To our delight we found that aroyl chlorides are indeed suitable coupling components with reactivities similar to aryl bromides (Fig. 4). [7]

A systematic optimization of the reaction conditions carried out by Heidi Landert, a very talented young technician, showed the following combination to be optimal for a variety of aroyl chlorides and activated alkenes: catalyst $\mathrm{Pd}(\mathrm{OAc})_{2}$, solvent $p$-xylene, base N-benzyl dimethyl amine at $100-130{ }^{\circ} \mathrm{C}$. Most reactions were carried out with $1 \%$ catalysts in 2-4 hours. It was possible to work with catalyst loadings as low as $0.001 \%$, albeit at incomplete conversion. Very good yields were obtained with electron-rich aroyl chlorides, whereas
Table 2. Important topics in catalysis R\&D at Ciba-Geigy/Novartis/Solvias in the area of C-C and

\begin{tabular}{|c|c|}
\hline Start & Topic / Milestone \\
\hline 1978 & $\begin{array}{l}\text { Investigations of the Heck reaction: Acid chlorides as starting materials; } \\
\text { high performance catalysts; Heck-Matsuda reaction for product discovery. }\end{array}$ \\
\hline ca. 1985 & Development of first industrial processes. \\
\hline 1995 & Ni catalysts for Suzuki coupling developed. \\
\hline 1998 & $\begin{array}{l}\text { Catalysts for the activation of aryl chlorides for Heck, Suzuki, Buchwald- } \\
\text { Hartwig amination etc.; secondary phosphines; palladacycles - secondary } \\
\text { phosphines as very efficient catalysts. }\end{array}$ \\
\hline 1998 & $\begin{array}{l}\text { Systematic investigation of the carbonylation of aryl halides; } \\
\text { carbonylation of (hetero) aryl chlorides. }\end{array}$ \\
\hline 2001 & Synthesis of small libraries via parallel carbonylation. \\
\hline ca. 2005 & $\begin{array}{l}\text { Production of commercial quantities of selected chiral ligands and } \\
\text { catalysts. }\end{array}$ \\
\hline
\end{tabular}

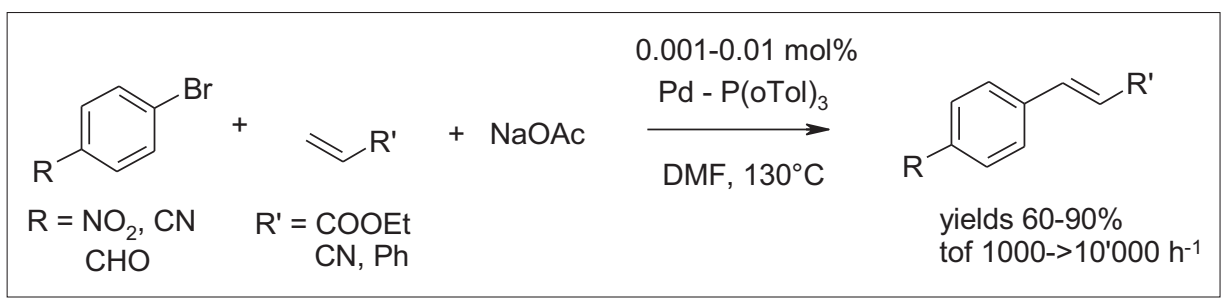

Fig. 3. The first high-performance catalytic system for the Heck reaction of activated aryl bro-

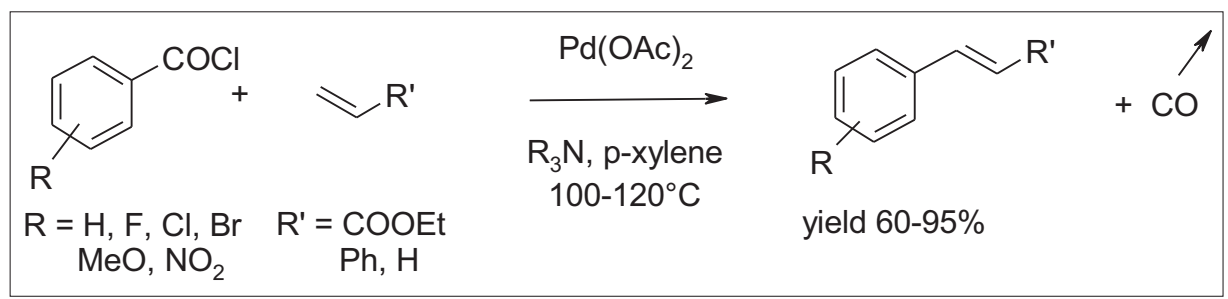

Fig. 4. The Blaser-Spencer variation of the Heck reaction. 
electron-deficient ones gave slightly lower yields, the reverse trend as observed for aryl halides. Other activated alkenes $\left(\mathrm{R}^{\prime}=\right.$ $\mathrm{Ph}, \mathrm{CONEt}_{2}, \mathrm{CN}, \mathrm{COMe}$ ) were also suitable coupling partners whereas disubstituted alkenes often led to isomeric mixtures. Since the reaction involves a decarbonylation, it is best performed in an open vessel to allow the CO to escape, which is a drawback of this method. Nevertheless, reactions with ethylene were possible under pressure with yields of up to $60 \%$. Tertiary amines were the bases of choice, but especially the more basic ones reacted with the aroyl chlorides. Phosphine ligands were shown to be detrimental and the presence of 2 moles completely blocked the reaction. This fact was exploited to selectively prepare non-symmetrically substituted divinylbenzenes starting from bromobenzoic acid derivatives.

This field of research developed very rapidly within Solvias and has led to many quite notable scientific and commercial successes, especially thanks to the efforts of Adriano Indolese, Anita Schnyder, Fred Naud and Ulrike Nettekoven (for details see ref. [6]). As a general conclusion one can state that the considerable R\&D carried out both in industrial and academic laboratories has paid off quite nicely and that $\mathrm{Pd}$ (and also $\mathrm{Ni}$ and $\mathrm{Cu}$ ) catalyzed $\mathrm{C}-\mathrm{C}$ and $\mathrm{C}-\mathrm{N}$ coupling, especially the Suzuki and Buchwald-Hartwig reactions are now well established in the fine chemicals industry as scalable methodologies for the manufacture of complex molecules.

\section{Hydrogenations Using Modified Heterogeneous Catalysts}

As already mentioned, in 1978 I moved to the catalysis section of the Katalyse/ Synthesedienste. This was quite a cultural change, since here the predominant topic was the application of heterogeneous catalysts both as a service for other research laboratories of Ciba-Geigy as well as in process development. With my background in organic chemistry and homogeneous catalysis, I had to learn not only about new catalyst types but - even more important - about different concepts developed over decades in this fascinating field. For a chemist who was used to understand catalysts and reactions in molecular terms it took some time getting used to terms such as active site, average particle size, dispersion or pore volume to characterize a catalyst. But eventually I learnt to master and appreciate what one could call the toolbox of heterogeneous catalysis as depicted in Fig. 5.

Of the many parameters of a heterogeneous catalyst that affect its catalytic performance, the following are the most

\begin{tabular}{|c|c|}
\hline \multicolumn{2}{|c|}{ - Active Phase (metal, metal oxide) } \\
\hline $\begin{array}{l}\text { - type, morphology, .... } \\
\text { - second metal }\end{array}$ & $\begin{array}{l}\text { NOT defined on molecular level } \\
\text { (controlled procedures; recipes) }\end{array}$ \\
\hline $\begin{array}{l}\text { - Support } \\
\text {-type, texture, chiral }\end{array}$ & $\begin{array}{l}\text { Surface science approaches } \\
\text { difficult }\end{array}$ \\
\hline \multicolumn{2}{|l|}{ - Modifier (promoter) } \\
\hline $\begin{array}{l}\text {-inorganic } \\
\text {-organic }\end{array}$ & Defined on molecular level \\
\hline $\begin{array}{l}\text {-chıral } \\
\text { - Reaction Medium } \\
\text {-solvent, additives }\end{array}$ & $\begin{array}{l}\text { Classical organic chemistry } \\
\text { approaches successful }\end{array}$ \\
\hline
\end{tabular}

Fig. 5. The toolbox of heterogeneous catalysis.

important ones: Type of metal (most often used $\mathrm{Pd}, \mathrm{Pt}, \mathrm{Ni}, \mathrm{Cu}, \mathrm{Rh}, \mathrm{Ru}$ ); type of catalyst (supported, powders, skeletal); metal loading of supported catalysts; type of support (active carbon, alumina, silica). Important parameters for the active metal are the surface area, the dispersion (typically only $10-60 \%$ of the metal atoms are exposed), the size of the crystallites (typically in the range $20->200 \AA$ ), the location in the pores of the support and oxidation state (reduced or unreduced). Important support parameters are the particle size (for slurry catalysts typically $1-100 \mu \mathrm{m}$ ), the surface area (typically in the range of $100-1500 \mathrm{~m}^{2} / \mathrm{g}$ ), the pore structure (pore volume, pore size distribution) and acid-base properties. Many types of heterogeneous catalysts are now available on a commercial basis but the choice of the optimal catalyst for a specific application requires a lot of practical experience. In this context, it is of advantage to develop a close working relationship with the catalyst producers specialized in catalysts for the fine chemical industry.

In cases where a commercially available catalyst lacks a desired property or selectivity, the addition of a modifier is an interesting option. Both organic molecules (e.g. amines, chiral modifiers such as cinchona alkaloids or tartaric acid) as well as inorganic salts/metals are known for this purpose. The modifier can either be added to the catalysts before it is introduced into the reaction (often done with inorganic compounds) or added directly to the reaction mixture as process modifier. Factors that may be influenced are catalyst selectivity, activity, reduction of intermediate/side product formation and catalyst recovery.

We extensively used the modification strategy for two very important reaction types: The chemoselective hydrogenation of substituted aromatic nitro compounds to the corresponding anilines and the enantioselective hydrogenation of ketones. I will only discuss the second topic in some detail, but would like to mention that the diligent work of Peter Baumeister, Heinz Steiner, Urs Siegrist, Wilfried Scherrer, Martin Studer and Hans Thies led to several very selective modified catalysts for the chemoselective reduction of functionalized nitroarenes which are now commercially available and marketed by Evonik. ${ }^{[8]}$

\section{Enantioselective Hydrogenation of Substituted Ketones using Chirally Modified Pt Catalysts}

In the early eighties, it became clear that racemic pharmaceuticals and agrochemicals would often be unacceptable to regulatory bodies and that enantioselective synthesis would become more and more important. With our background in heterogeneous hydrogenation we noticed with interest the results on hydrogenation catalysts modified with chiral auxiliaries reported by several Japanese groups. Of particular significance to us were the tartrate-modified nickel catalysts and the amazing results described by Orito for the enantioselective hydrogenation of $\alpha$-ketoesters using Pt catalysts modified with cinchona alkaloids (Fig. 6). Both catalytic systems achieved enantioselectivities of almost $90 \%$, at the time very encouraging values, and we decided to start a small research program in this area. While we also tried to reproduce and improve on the modified nickel system we quickly focused on the Pt-cinchona catalysts for two reasons: First, the catalysts could be modified in situ, i.e. did not require a difficult catalyst preparation as was the case for the Ni catalysts. Secondly, a few months after the start of the program our colleagues of pharma development asked our help to find an enantioselective catalyst to make methyl $(R)$-2-hydroxy-4-phenyl butyrate (HPB ester, Fig. 6). In the following, I will describe some of our efforts to adapt the Orito catalyst to industrial application as well as our attempts to unravel its mode of action. ${ }^{\text {9] }}$ 


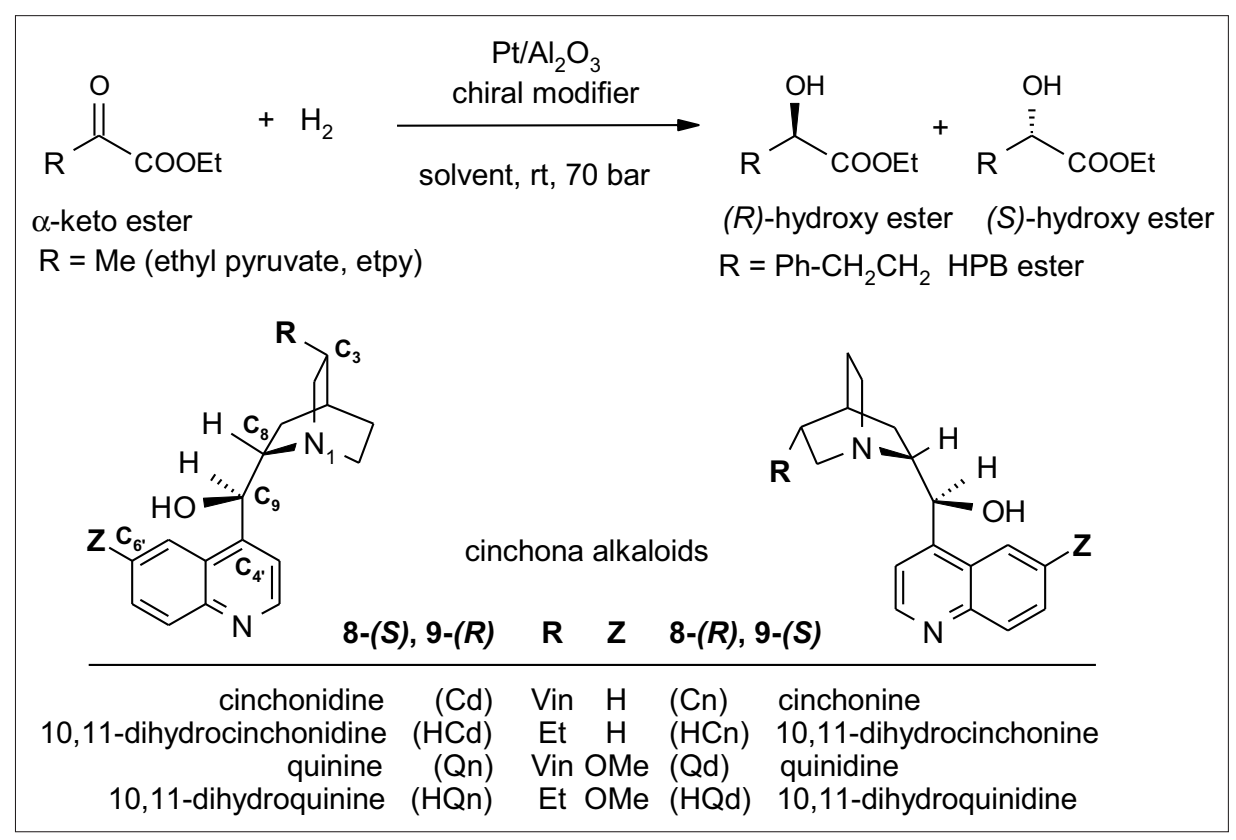

Fig. 6. The Orito reaction.

\section{Finding Suitable Catalysts}

When we started our investigations and tried to reproduce some of Orito's results, we noticed immediately that this might become more cumbersome than anticipated. We were of course familiar with the problem that heterogeneous catalysts cannot be characterized on a molecular level and that reproducibility is often an issue for catalytic processes. For this reason, we have learnt to rely on the expertise and quality control of the major suppliers of hydrogenation catalysts. In this case two facts made the situation more difficult. First, most of Orito's publications were in Japanese, so it took some time to understand them and, secondly, the catalysts he used were neither available in Europe nor well characterized. In this situation we decided to turn to a catalyst expert and started a joint project with Alfons Baiker (ETH Zürich). Under the guidance of Daniel Monti (a former Baiker student), Jürg Wehrli prepared and characterized around 100 different $\mathrm{Pt} /$ alumina catalysts and tested them for the hydrogenation of ethyl pyruvate. ${ }^{[10]}$ The results can be summarized as follows:

- We could reproduce and in some cases surpass the results described by Orito achieving $e e$ values up to $91 \%$.

- The platinum dispersion and the method of catalyst preparation had a decisive influence on the catalytic performance. In order to get high enantioselectivity, the platinum dispersion should be lower than $0.2-0.3$. There also were some indications that flat $\mathrm{Pt}$ surfaces are favorable.

- Two commercial $5 \% \mathrm{Pt} / \mathrm{Al}_{2} \mathrm{O}_{3}$ catalysts showed superior performance: $\mathrm{E}$ 4759 from Engelhard and JMC 94 from Johnson Matthey. While both catalysts
Nevertheless, we had the impression that a fast reaction often indicated good enantioselectivity. This was a bit surprising since it is quite common that a modified heterogeneous catalyst is less active, i.e. an increase in selectivity has often to be "paid for' with a decrease in activity. For this reason we decided to have a closer look at the kinetics of the modified catalyst. We were lucky that at this point Marc Garland, a chemical engineer and mathematical wizard, joined our group as a Postdoc and got interested in the problem. He started a systematic investigation of the effect of various reaction parameters, especially the modifier concentration. He very quickly found that already rather small modifier concentrations are effective and that $e e$ and rate increased with increasing cinchona concentration and that the two effects are somehow linked to each other as illustrated by Fig. 7. However, the different shape of the $e e$ and rate curves was puzzling. By an interesting coincidence, Sharpless and coworkers $^{[11]}$ reported similar behavior for the Os-catalyzed dihydroxylation of olefins with a cinchona alkaloid as chiral ligand just at this time. They coined the term 'ligand acceleration' for this phenomenon, where a non-chiral but catalytically active catalytic species can be rendered enantioselective and faster by reversible coordination of a chiral ligand. Marc very quickly developed the appropriate kinetic models for the Pt-cinchona system, assuming that the cinchona modifier reversibly adsorbs on the surface of the Pt catalyst, thereby creating highly active chiral sites. ${ }^{[12]}$ In this model, the resulting ee will depend on the ratio of modified to unmodified sites and on the relative turnover frequencies of the three cycles schematically depicted in

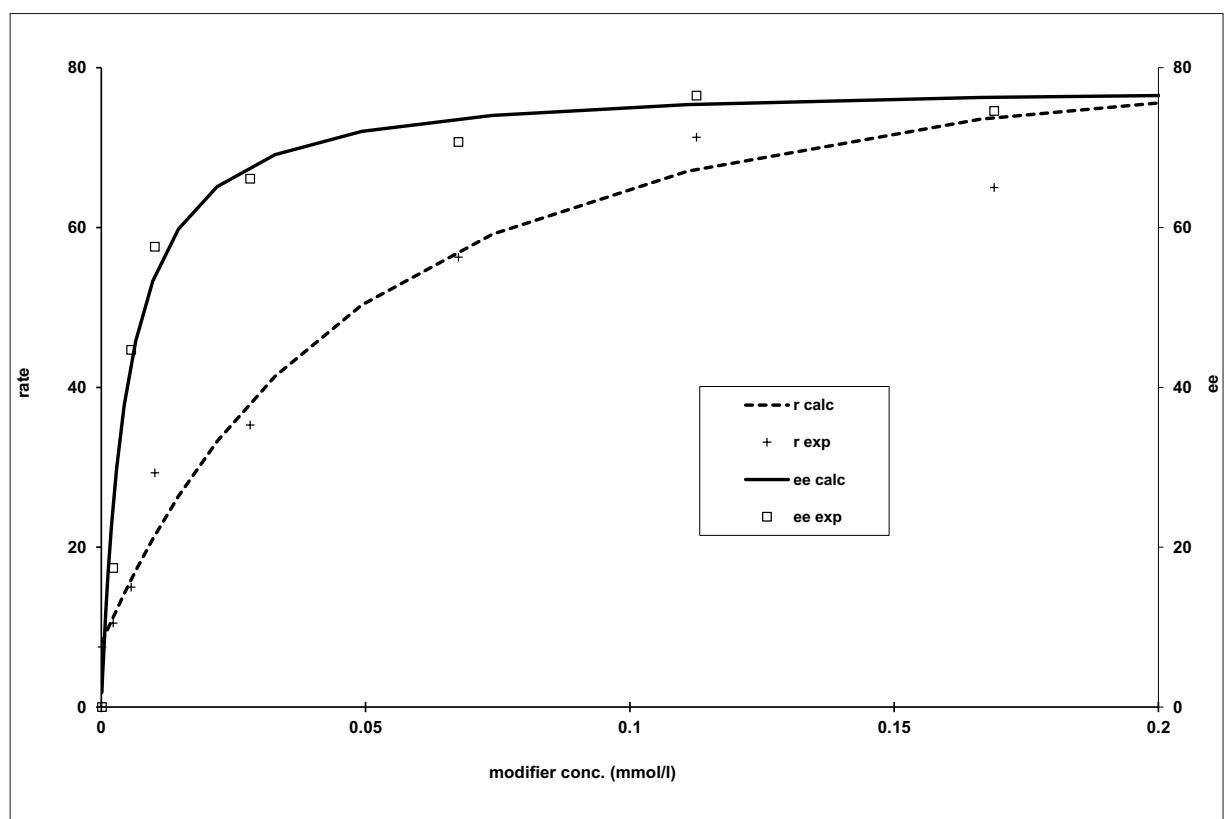

Fig. 7. Hydrogenation of ethyl pyruvate: Rate and ee versus modifier concentration $\left(\mathrm{Pt} / \mathrm{Al}_{2} \mathrm{O}_{3}\right.$, dihydrocinchonidine, 20 bar in $\mathrm{EtOH}$ ). 


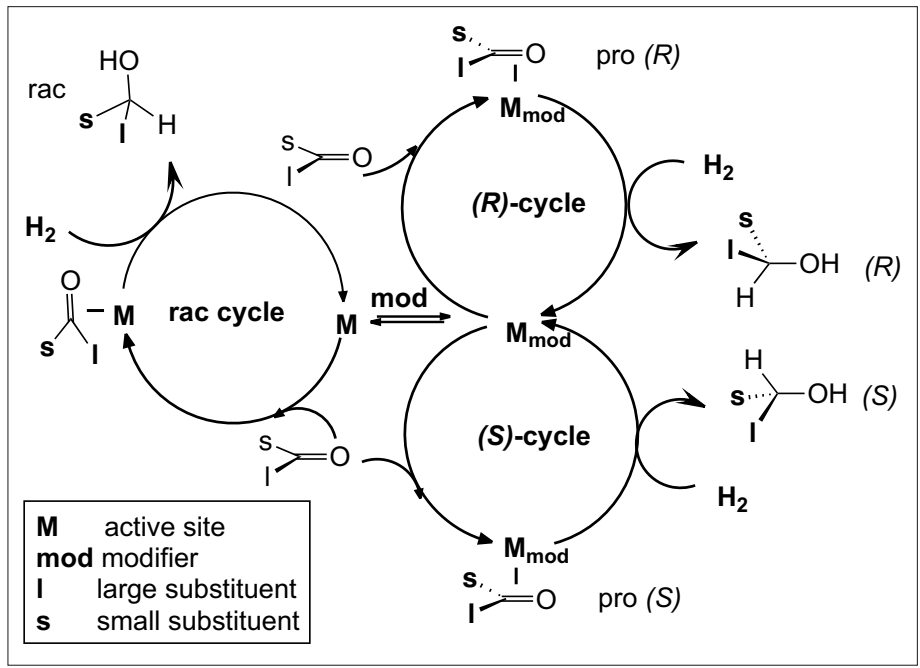

Fig. 8. Schematic catalytic cycles for the hydrogenation of ketones on a partially modified catalyst.
Fig. 8. This simple kinetic model with a slow, racemic reaction on the unmodified catalyst and an about 10 times faster reaction with an $e e$ around $80 \%$ on the modified sites gave a very good fit to the measured data in ethanol. In contrast to a homogeneous catalyst, neither the exact nature nor the number of active sites on a metal surface can be determined. This could be a single Pt atom or (more likely) ensembles of atoms. Furthermore, it is not sure that all catalytically active sites can be modified by the relative large cinchona molecule and as a consequence it is not possible to determine the absolute values of the rate and adsorption constants.

In toluene and $\mathrm{AcOH}$, the situation was even more complicated. In toluene, the maximum ee was reached at lower $\mathrm{HCd}$ concentration than in $\mathrm{EtOH}$, and both $e e$ and rate decreased when the modifier concentration was increased further. This dependence on rate and ee can also be modeled assuming that at higher modifier concentration, a third type of active site with lower enantioselectivity and lower activity replaces $\mathrm{M}_{\bmod }$ and an example of such a rate vs. ee curve is depicted in Fig. 9. ${ }^{[13]}$ Later we found that this phenomenon is quite general and can be observed with a variety of different substrates, solvents, modifiers and catalyst types.

Encouraged by these results, we decided to carry out a full kinetic investigation for the hydrogenation of methyl pyruvate with and without dihydrocinchonidine. [14] The effects of catalyst loading, modifier and substrate concentrations, hydrogen pressure, and temperature on the rate of the unmodified and on rate and $e e$ of the modified system were studied. All results were compatible with a Langmuir-Hinshelwood description where the basic catalytic cycle consists of a fast adsorption of ketone and hydrogen on the Pt surface, the stepwise addition of the two adsorbed hydrogen atoms to the $\mathrm{C}=\mathrm{O}$ bond with a half-hydrogenated intermediate and finally the fast desorption

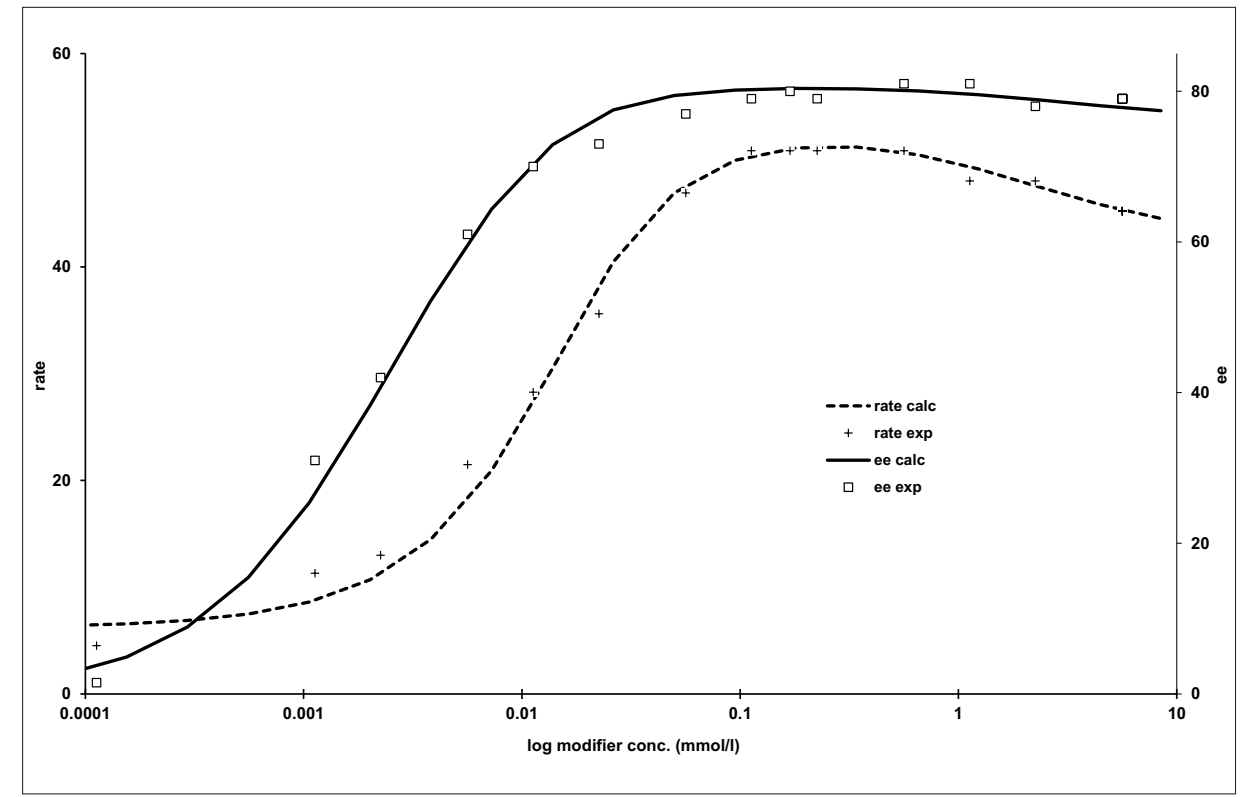

Fig. 9. Hydrogenation of ethyl pyruvate, rate and ee versus logarithmic modifier concentration ( $\mathrm{Pt} / \mathrm{Al}_{2} \mathrm{O}_{3}$, dihydrocinchonidine, 20 bar in toluene).

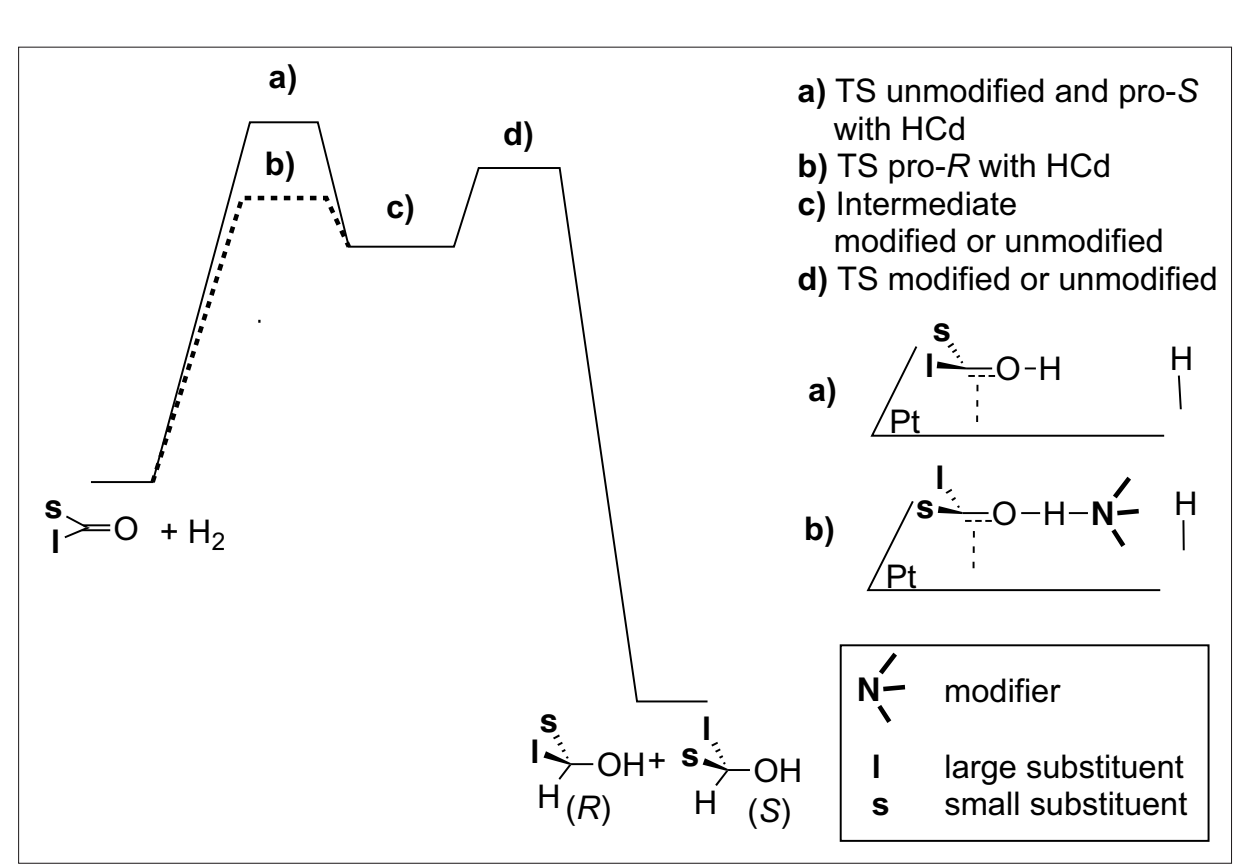

Fig. 10. Schematic energy diagram for the hydrogenation of a $\alpha$-keto ester with and without

cinchona modifier. of the alcohol. Our results indicated that the observed rate acceleration can be explained by a shift of the rate determining step for one of the two possible adsorbed forms of ethyl pyruvate as depicted schematically in Fig. 10.

A first qualitative model involving a cinchona modifier $\pi$-bound to the Pt surface via the quinoline ring and attractive interactions between the quinuclidine nitrogen and the adsorbed ketone was put forward after modified cinchona molecules were prepared and tested (see next section). ${ }^{[15]}$ This basic model was able to explain many of the most important experimental facts. It was refined and supported by a variety of very elegant and sophisticated surface science, spectroscopic as well as com- 
putational investigations especially by the groups of Baiker ${ }^{[16]}$ and McBreen. ${ }^{[17]}$ Nevertheless, the specific (attractive and repulsive) interactions between adsorbed substrate and modifier which lead to the observed stereo differentiation are still under hot debate and two competing but plausible models are depicted in Fig. 11.

\section{The Quest for the Perfect Modifier}

There is no doubt that the cinchona alkaloids selected by Orito are very effective modifiers for the Pt-catalyzed hydrogenation of $\alpha$-keto esters. Nevertheless, there were a few drawbacks and we had a lot of questions concerning their mode of action. As a consequence, we started a screening program to find alternative modifiers and we synthetically altered the parent alkaloids depicted in Fig. 6. The screening for alternative modifiers failed miserably, even though we tested about 100 different chiral auxiliaries, we never found any meaningful enantioselectivity. The modification of the cinchona derivatives was carried out by Willi Lottenbach and was much more fruitful. After a detailed study of the hydrogenation of ethyl pyruvate with a variety of different cinchona derivatives we concluded ${ }^{[18]}$ that three structural elements in the cinchona molecule were crucial: i) an extended aromatic moiety, ii) the substitution pattern of the quinuclidine (the absolute configuration at $\mathrm{C}_{8}$ controls sense of induction), iii) the substituents at $\mathrm{C}_{9}(\mathrm{OH}$ or $\mathrm{MeO}$ is optimal, larger groups reduce enantioselectivity and in some case even lead to inversed induction).

A different approach to understand the importance of various structural elements was the synthesis of cinchona mimics. First studies by Pfaltz and Baiker indicated that good enantioselectivities can be reached with relatively simple amino alcohols having just one stereogenic center (best modifiers see Fig. 12). ${ }^{[19]}$ Since synthetic modifiers would allow the preparation of both product enantiomers with equal enantioselectivity, we undertook a joint research project with Andreas Pfaltz (University of Basel). In an in-depth study, Christian Exner[20] synthesized various cinchona analogs with a systematic variation of the aromatic part and the chiral amino group as depicted in Fig. 12, and carried out tests with a set of different substrates.

From his data, the following conclusions were drawn ${ }^{[21]}$

- It was confirmed that the presence of an extended aromatic system with a chiral group carrying an amino function is necessary but not a sufficient prerequisite for high enantioselectivity.

- For every substrate the highest ee values were obtained with quinuclidinederived modifiers in combination with naphthalene or quinoline rings.

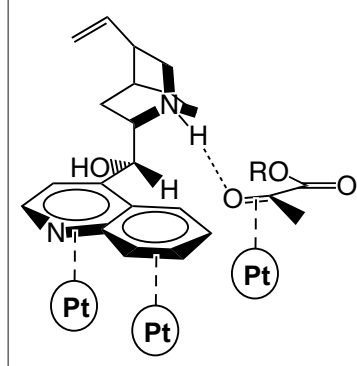

Baiker's mode

$\mathrm{N}-\mathrm{H}$ bonding to keto group

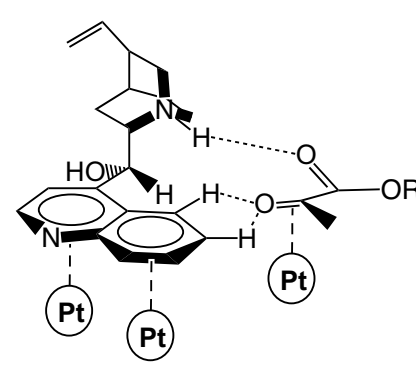

McBreen's model

$\mathrm{N}-\mathrm{H}$ bonding to ester carbonyl $\mathrm{C}$ - $\mathrm{H}$ bonding to keto group

Fig. 11. Schematic presentation of the activated surface complex.

\section{best results in initial study}<smiles>OC(CN1CCCC1)c1cccc2ccccc12</smiles>

$75 \%$ ee

aromatic moiety<smiles>[R7]c1ccc2nccc(C)c2c1</smiles><smiles>Cc1cccc2ccccc12</smiles><smiles>Cc1c2ccccc2cc2ccccc12</smiles><smiles>OC(CN1CCCC1)c1c2ccccc2cc2ccccc12</smiles>

$87 \%$ ee
Fig. 12. Structures of cinchona derivatives and mimics.
- The substituent $\mathrm{R}^{\prime}$ at the quinuclidine system has a more important influence than previously thought and can significantly affect the ee compared to the unsubstituted derivatives (positive and negative effects!).

- Both bicyclic and tricyclic aromatic systems rings can lead to high enantioselectivity. For the sterically more demanding and more rigid quinuclidine, quinoline and to some lesser extent naphthalene were a better match, while for the smaller pyrrolidinylmethyl group anthracene was superior.

- $\mathrm{HCd}$ and $\mathrm{HCn}$ derivatives usually gave higher $e e$ values than the corresponding Qn and Qd which carry a methoxy substituent at the quinoline system.

- Methylation of the $\mathrm{OH}$ group often had a positive effect for hydrogenations in $\mathrm{AcOH}$ but not in toluene.

Some of the new modifier-substrate combinations give significantly higher enantioselectivity than previously reported, especially for the $(S)$-products. These results will be a useful basis for further optimization of the modifier structure as well as the development of modifiers for other substrates.

\section{Expanding the Substrate Scope}

It is well recognized that most enantioselective catalysts are rather substrate specific. Once we had found an effective 
catalyst for the hydrogenation of $\alpha$-keto esters, we wanted to find other suitable substrates with broad applicability. Since $\alpha$-keto esters tend to side reactions, HansPeter Jalett[22] prepared and reduced a number of the more stable $\alpha$-keto acids. However, even this small variation led to decreased enantioselectivities (usually below $80 \%$ ee) despite an extensive optimization of the reaction parameters. The corresponding $\mathrm{Na}$ or $\mathrm{K}$ salts even gave racemic products! Satisfactory enantio- and very high chemoselectivities were achieved for the hydrogenation of $\alpha, \gamma$-diketoesters ${ }^{[23]}$ (also see industrial applications below) and as described by the Baiker group, ${ }^{[24]}$ also for ketopantolacton and $\alpha$-ketoimides.

Since $\alpha$-hydroxy acetals and ethers are valuable building blocks, Martin Studer started to investigate the hydrogenation of the corresponding ketones. To our delight, enantioselectivities $>90 \%$ were obtained for $\alpha$-ketoacetals ${ }^{[25]}$ as well as for $\alpha$-ketoethers, $\left.{ }^{2} 26\right]$ where dynamic kinetic resolution yielded high $e e$ and $d e$ values with racemic starting materials. The hydrogenation of 1,2-butanedione ${ }^{[27]}$ to the hydroxy ketone occurred with significantly lower enantioselectivities, which increased during the reaction because the minor enantiomer reacted significantly faster to the corresponding diol (kinetic resolution). Baiker ${ }^{[28]}$ showed that $\alpha$-fluorination, especially the trifluoromethyl group, has an activating effect comparable to an ester group. Indeed the hydrogenation of trifluoro acetoacetate as well as of various trifluoro acetophenones was reported with up to $93 \%$ ee.

Despite significant progress in the last years, the synthetically useful substrate scope of the cinchona-modified platinum catalysts is still relatively narrow (Fig. 13). Various attempts were made to modify other metals with cinchona alkaloids and to extend the scope to the hydrogenation of $\mathrm{C}=\mathrm{C}$ bonds. However, with few exceptions enantioselectivities and often catalytic activities were too low to be of practical interest.

\section{Technical Processes}

As described in the introduction, a few months after we started to investigate the Orito system, our colleagues from pharma development asked for our help to find an enantioselective catalyst to make methyl $(R)$-2-hydroxy-4-phenyl butyrate (HPB ester), a key intermediate for the synthesis of benazepril, an ACE inhibitor then under development (Fig. 14). Since at the time homogeneous hydrogenation as well as biocatalytic reductions were not established for $\alpha$-keto acid derivatives, the results described by Orito looked very promising.

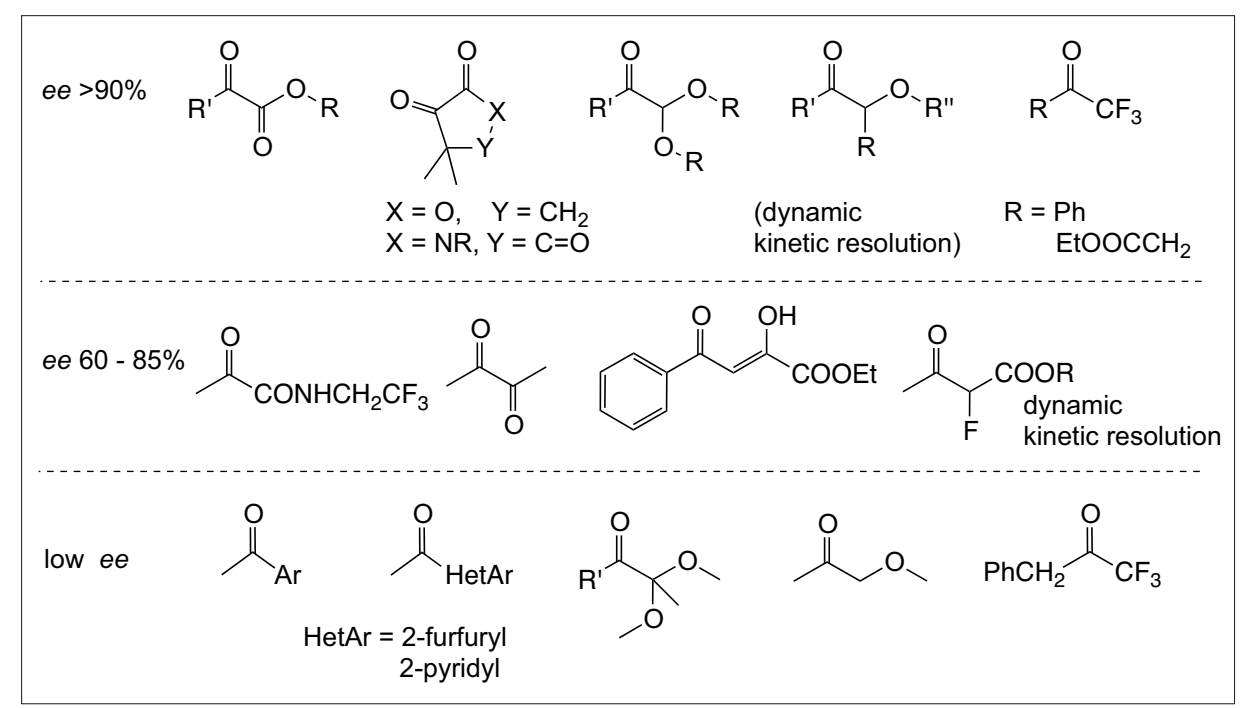

Fig. 13. Structures of 'good', 'medium', and 'bad' ketone substrates for cinchona-modified Pt catalysts.

Since the reproduction of Orito's results turned out to be more difficult than expected, the development of a viable process for the HPB ester took more than a year even though the experienced HansPeter Jalett took care of the experiments. Even before the age of high-throughput screening, the obvious strategy was first to screen for the best catalyst, modifier and solvent, secondly, to optimize relevant reaction parameters $(\mathrm{p}, \mathrm{T}$, concentrations etc.) and, finally, to scale up and solve relevant technical questions. Indeed, in the course of process development, Jalett carried out more than 200 hydrogenation reactions. The most important results of this development work can be summarized as follows:

- Catalyst: $5 \% \mathrm{Pt} / \mathrm{Al}_{2} \mathrm{O}_{3}$ catalysts gave the best over-all performance and the E 4759 from Engelhard was the final choice.

- Modifier: About 20 modifiers were tested; $\mathrm{HCd}$ (in toluene) and $\mathrm{MeOHCd}$ (in $\mathrm{AcOH}$ ) gave best results and were chosen for further development.

- Solvent: Jalett found that acetic acid was far superior to all classical solvents, allowing up to $92 \%$ ee for the HPB ester and $95 \%$ for ethyl pyruvate (then a new world record!).[29] For technical reasons toluene was chosen as solvent for the production process.

- Reaction conditions. Best results (full conversion after $3-5 \mathrm{~h}$, high yield, $80 \%$ ee) were obtained at 70 bar, rt with $0.5 \% \mathrm{w} / \mathrm{w} 5 \% \mathrm{Pt} / \mathrm{Al}_{2} \mathrm{O}_{3}$ (pre-treated in $\mathrm{H}_{2}$ at $400{ }^{\circ} \mathrm{C}$ ) and $0.03 \%$ w/w modifier.

- Substrate quality. Enantioselective hydrogenation of $\alpha$-ketoesters proved to be exceptionally sensitive to the origin of the substrate.[30]

After about two years, the production process was developed, patented ${ }^{[31]}$ and scaled up and 1987 a few hundred kilo- grams were successfully produced in a 500 1 autoclave. The progress of the optimization can best be demonstrated by the variations in $e e$ versus the experiment number in the different development phases (Fig. 15). The effect of various measures can be seen that led to improved enantioselectivities and a stabile process. Despite this success, pharma production eventually decided to buy $(R)$-HPB ester from an external supplier.

A few years later, a new process for the $(R)$-HPB ester was developed in collaboration with Ciba SC Life Science Molecules. After assessing a variety of synthetic routes, we focused on the one depicted in Fig. 16: Claisen condensation of cheap acetophenone and diethyl oxalate, followed by chemo- and enantioselective hydrogenation of the resulting diketoester and hydrogenolysis to the HPB ester. ${ }^{[32]}$ Even though the 2,4-dioxo ester was a new substrate type, it took only a few months to develop, scale-up and implement the new process. Key steps in the new process are undoubtedly the hydrogenation of the 2,4-dioxo ester with excellent chemo- and satisfactory enantioselectivities and the successful enrichment to $>99 \%$ ee via crystallization.

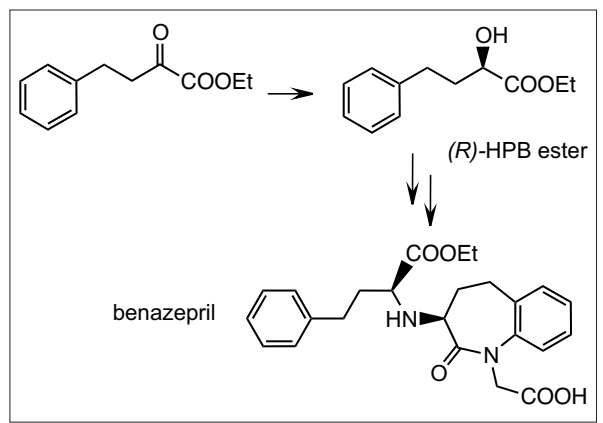

Fig. 14. Synthesis of benazepril. 


\section{Conclusions and Outlook}

In the last two decades, significant progress has been made in the area of enantioselective hydrogenation using chirally modified heterogeneous catalysts. This is true in respect to understanding the mode of action of the catalytic systems as well as from a synthetic and industrial point of view. Obviously our focus was more on synthetic applications but in order to develop reproducible processes we also benefited from kinetic studies. Our work has shown that selected modified catalysts are indeed industrially viable and that in favorable cases they can compete with homogeneous as well as with biocatalytic alternatives. However, the scope of this technology is still restricted to the hydrogenation of ketones activated in the $\alpha$ or $\beta$ position and, furthermore, the mechanistic understanding of even the best characterized catalysts is still relatively poor compared to homogeneous catalysts. For this reason we do not expect a fast progress or a breakthrough in the near future.

\section{Enantioselective Homogeneous Hydrogenation and Chiral Ligands}

As described above, at beginning of the 1980s we began to realize the potential of enantioselective catalysis and the metolachlor project (see below) gave us the necessary incentive to start a research project using chiral homogeneous catalysts.

The first enantioselective homogeneous catalysts were described in 1968 by the groups of Knowles and Horner and during the seventies many publications appeared on this topic. ${ }^{[33]}$ However, in 1981 only one asymmetric catalytic reaction was applied industrially, namely the enantioselective hydrogenation of an enamide with a soluble $\mathrm{Rh}$-dipamp complex for the production of L-dopa by Monsanto. This success was the major reason that during the next decade, the hydrogenation of enamides became the best studied catalytic asymmetric reaction. Countless new chiral ligands were synthesized and tested with different enamides and the basic reaction mechanism was unraveled. The best catalyst gave up to $99 \%$ e $e^{[34]}$ but turnover numbers were relatively modest. For the hydrogenation of $\mathrm{C}=\mathrm{O}$ groups $\mathrm{Rh}$-diphosphine catalysts were also reported to give $e e$ values up to $95 \%$ ee but without any data on activity. ${ }^{[35]}$ In contrast, the enantioselective catalytic reduction of $\mathrm{C}=\mathrm{N}$ functions was practically unknown (see below).

At that time less than 10 chiral diphosphine ligands were commercially available and of course only in small quantities.

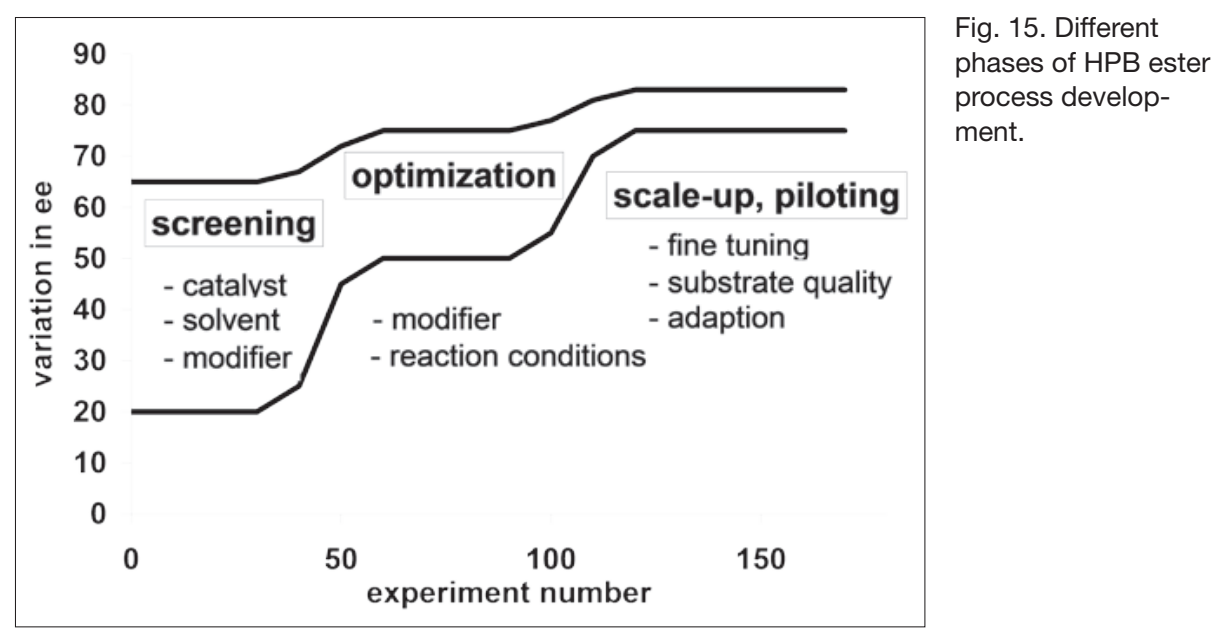

Over all yield: $\mathbf{5 0 - 6 0 \%}$

Fig. 16. Improved synthesis of HPB ester.
This made life very difficult for industrial groups because it severely hampered an efficient process development.

Concerning our own circumstances: While the Catalysis Section of Ciba-Geigy had a history dating back to the early thirties, its expertise was concentrated on the application of heterogeneous hydrogenation. In the areas of homogeneous catalysis, the major fields of research were $\mathrm{Ni}$ - and Pd-catalyzed $\mathrm{C}-\mathrm{C}$ bond formation, organometallic chemistry and a few preparative applications of Wilkinson's catalyst. However, we had never used a chiral metal complex and our hydrogenation equipment was not well suited for handling homogeneous catalysts. This means that at the same time when we started the $(S)$-metolachlor project, we also launched our research activities in the field of enantioselective catalysis - certainly not an ideal situation!

\section{The Chiral Switch of Metolachlor}

\section{Background}

Metolachlor is the active ingredient of Dual ${ }^{\circledR}$, one of the most important grass herbicides for use in maize. It is an $\mathrm{N}$-chloroacetylated, N-alkoxyalkylated $\mathrm{or}$ tho-disubstituted aniline. Metolachlor has two chiral elements: a chiral axis (due to hindered rotation around the $\mathrm{C}-\mathrm{N}$ axis) and a stereogenic center, leading to four stereoisomers (Fig. 17). Dual ${ }^{\circledR}$ was introduced to the market by Ciba-Geigy in 1976 as a mixture of all four stereoisomers produced via the $\mathrm{Pt} / \mathrm{C}$ catalyzed reductive alkylation of 2-methyl-5-ethyl-aniline (MEA) with aqueous methoxyacetone in the presence of traces of sulfuric acid followed by chloroacetylation (Fig. 18).[36]

In 1982 it was found that about $95 \%$ of the herbicidal activity of metolachlor resides in the two (1'S)-diastereomers, i.e. is mainly controlled by the absolute configuration of the stereogenic center of the side chain. ${ }^{[37]}$ This means that with enriched material the same biological effect could be achieved with about $65 \%$ of the racemate, no small matter considering that $>20,000$ metric tons of this herbicide were produced, shipped and applied every year! This finding initiated the search for a suitable catalyst to enantioselectively produce (S)-metolachlor, a search which lasted more than a decade and resulted in the largest enantioselective catalytic process in industry. A list of important milestones is given in Table 3.

The story of the chiral switch of metolachlor and the discovery of the Ir-Josiphos catalyst has already been described in great detail. ${ }^{[38,39]}$ Here I will summarize the most important milestones and will discuss the lessons learnt over the years since these 
strongly affected our strategies concerning process development and the buildup of a ligand portfolio for enantioselective hydrogenation.

\section{A Tough Start}

In an extensive project study carried out in 1981 we came up with the four routes shown in Fig. 19 and assessed in Table 4. Three synthetic routes were tested experimentally: i) Enamide hydrogenation (inspired by the successful L-dopa process of Monsanto, ${ }^{[40]}$ ) ii) nucleophilic substitution of an $(R)$-methoxyisopropanol derivative with the enantioselective hydrogenation of methoxyacetone as key step (by analogy to Pt-cinchona catalyzed hydrogenation of $\alpha$-ketoesters as described above) and iii) the hydrogenation of MEA imine. Because enantioselective reduction was considered to be the key step, the enamide and substitution routes were tested first.

After more than a year, we had to acknowledge complete failure: none of the three enamides showed any(!!) conversion with seven different $\mathrm{Rh}$ diphosphine catalysts at temperatures up to $50^{\circ} \mathrm{C}$ and 1 bar. Methoxyacetone could be hydrogenated with a cinchonidine-modified $\mathrm{Pt} / \mathrm{C}$ catalyst but enantioselectivity never exceeded $12 \%$. This left the hydrogenation of MEA imine as the only realistic possibility.

In retrospect it can be asked why the imine hydrogenation was not considered as first priority. Because the racemic metolachlor was commercially produced via a reductive alkylation, it should have been obvious to try to hydrogenate the imine intermediate, either isolated or formed in situ. The answer can be found in Fig. 20: At the beginning of the 1980s just a few publications described the enantioselective reduction of imines. Most of the results were obtained with heterogeneous catalysts, except for a Rh-diop catalyzed hydrosilylation ee values never exceeded $25 \%$ and no results for $\mathrm{N}$-aryl imines were published. As a consequence, we predicted a lengthy development to achieve our goal - little did we know how accurate this prediction was!

\section{Imine Hydrogenation: Initial Success}

First positive results were obtained by a UBC team which adapted Rh-diphosphine catalysts originally developed for alkene hydrogenation. The most effective catalyst, Rh-cycphos, achieved up to $69 \%$ ee at $-25{ }^{\circ} \mathrm{C}$ (Fig. 21). ${ }^{[41]}$ Despite rather low activities, these results represented a breakthrough in enantioselective $N$-aryl imine hydrogenation.

Inspired by results of Crabtree ${ }^{[42]}$ who had described an extraordinarily active, albeit achiral Ir catalyst for the hydrogenation of tetra-substituted $\mathrm{C}=\mathrm{C}$ bonds,

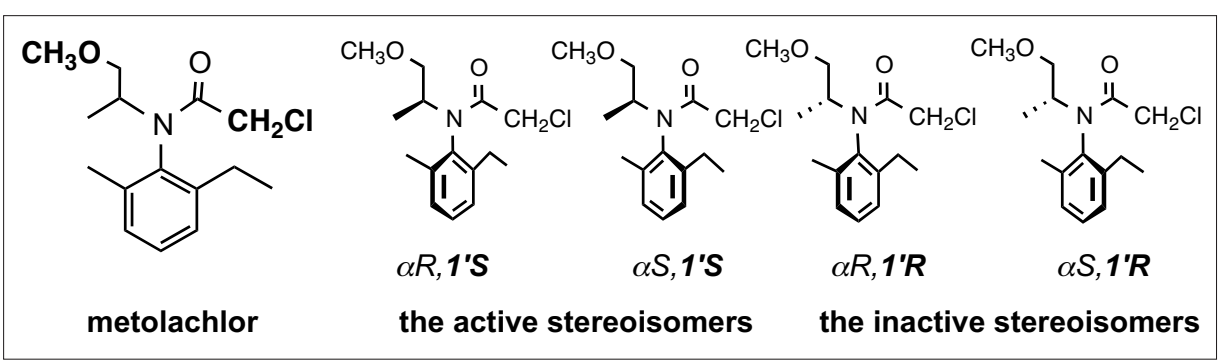

Fig. 17. Structure of metolachlor and its individual stereoisomers.

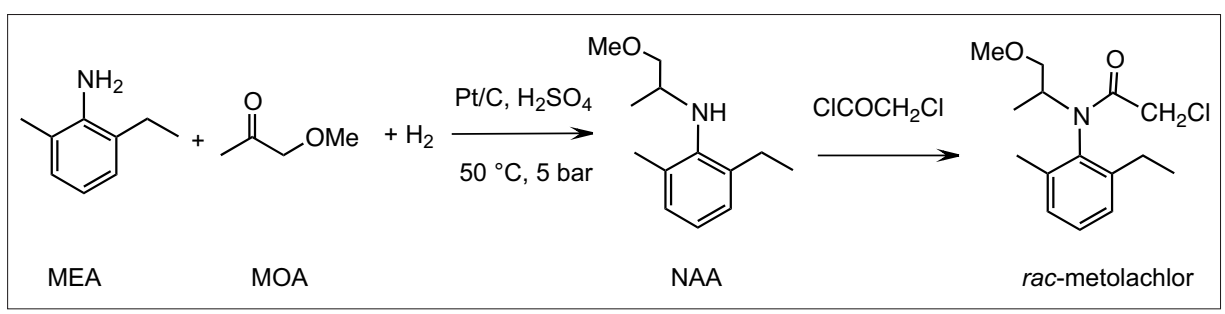

Fig. 18. Industrial process for rac-metolachlor.

Table 3. Milestones in the history of metolachlor

1970 Discovery of the biological activity of racemic metolachlor.

1978 Full-scale plant with a production capacity $>10,000$ tons/y in operation.

1982 Synthesis and biological tests of the four stereoisomers of metolachlor.

1985 Rhodium / cycphos catalyst gives 69\% ee for the imine hydrogenation (University of British Columbia (UBC), Vancouver).

1987 New iridium diphosphine catalysts are more active and selective (up to 84\% $e e)$ than rhodium catalysts; catalyst deactivation is a problem.

1992 Novel ferrocenyl ligands are developed, leading to very active catalysts without deactivation problems.

1993 The acid effect is discovered and a laboratory process with Ir-Xyliphos is established.

1995/6 Pilot results for $(S)$-metolachlor: ee 79\%, turnover number 1,000,000, turnover frequency $>200,000 / \mathrm{h}$, first 300 tons produced.

1996 Full-scale plant for production of $>10,000$ t/y $(S)$-metolachlor starts operation.

Felix Spindler decided to focus on iridium instead of rhodium complexes. Very soon thereafter, impressive progress was forthcoming. For the MEA imine hydrogenation an Ir-bdpp catalyst gave up to $84 \%$ ee at $0{ }^{\circ} \mathrm{C}$ although with low turnover numbers. On the other hand, Ir-diop reached up to 10,000 turnovers, but with lower ee values (Fig. 21).[43]

A major problem associated with these Ir catalysts was irreversible catalyst deactivation, probably via dimerization of the active Ir complexes. Similar problems had already been observed by the Crabtree group and we tried several strategies to prevent dimerization. In collaboration with J. A. Osborn, my postdoc adviser who had moved to the University of Strasbourg, we studied the nature of the active species. Felix Spindler tried to prevent dimerization by complexation with stabilizing additives. Both approaches gave interesting results but did not solve our problem.
Benoit Pugin decided to focus on immobilization of diphosphine ligands via covalent linkages. He developed a modular system of supports (polymer, silica), linkers and appropriately functionalized ligands which allowed him to tailor the immobilized catalyst to a specific reaction. In 1990 he reported a first success: Supported Ir-bpm catalysts showed about 3-8 times higher activities compared to the homogeneous analogs; on second use, turnover frequency was higher by a factor of $>20$. Even though these results were very promising and at that time represented by far the best catalyst performance for enantioselective imine hydrogenations, it was clear that the ambitious goals for a technical process ( $\geq 80 \%$ ee $,>50,000$ turnovers, $<8 \mathrm{~h}$ reaction time) could probably not be reached using Ir complexes with 'classical' diphosphine ligands. A new approach was clearly required. 


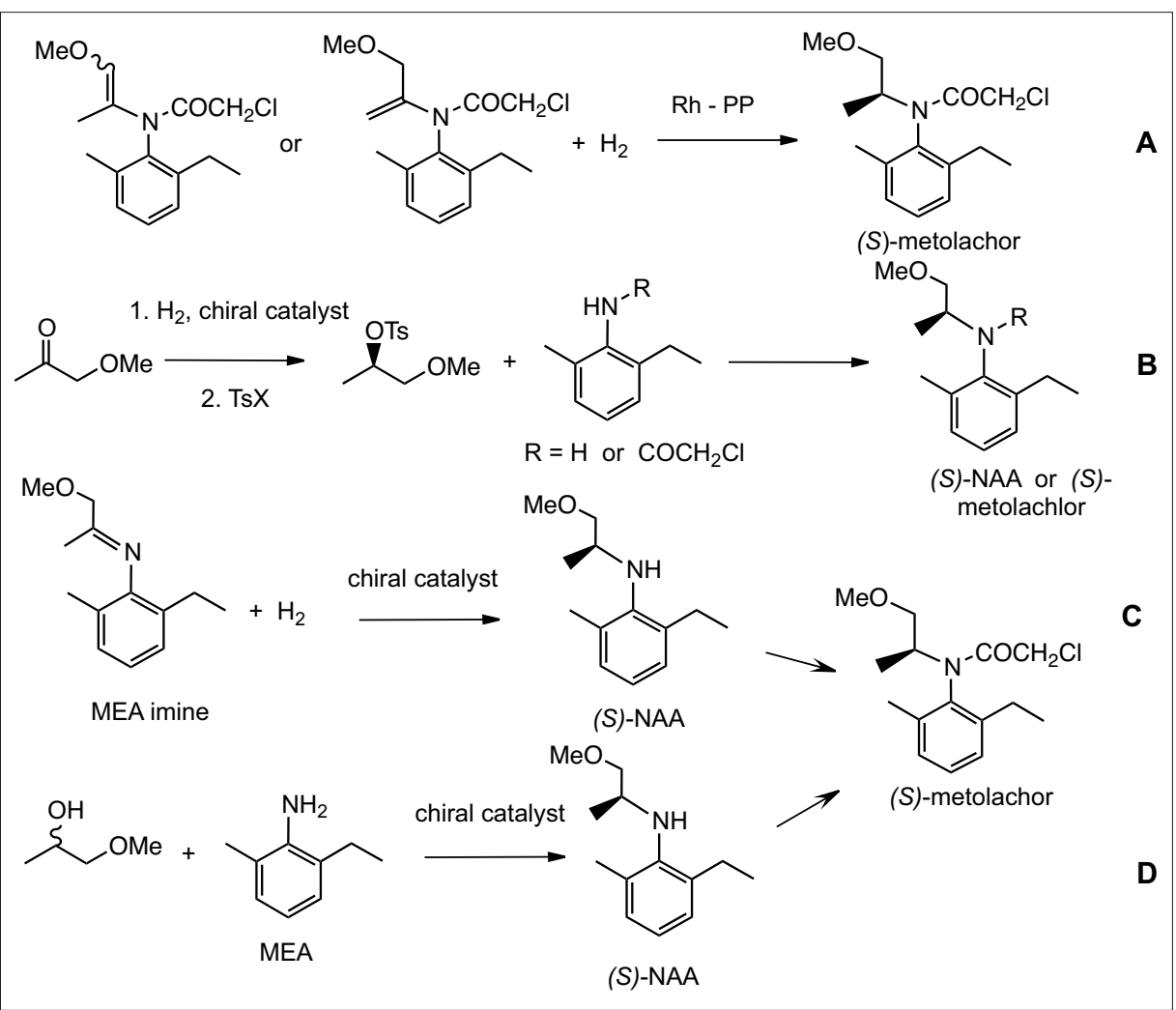

Fig. 19. Routes to (S)-metolachlor.

Table 4. Assessment of possible routes for the synthesis of (S)-metolachlor

\begin{tabular}{|l|c|c|c|c|}
\hline route & catalytic step & other steps & $\begin{array}{c}\text { cost } \\
\text { (ecology) }\end{array}$ & priority \\
\hline A: enamide & $\begin{array}{c}\text { close analogy } \\
e e>90 \%\end{array}$ & $\begin{array}{c}\text { enamide synthesis } \\
\text { difficult }\end{array}$ & $\begin{array}{c}\text { high } \\
\text { (medium) }\end{array}$ & $\mathbf{1}$ \\
\hline B: substitution & $\begin{array}{c}\text { weak analogy } \\
e e>80 \%\end{array}$ & $\begin{array}{c}\text { substitution very } \\
\text { difficult }\end{array}$ & $\begin{array}{c}\text { high } \\
\text { (bad) }\end{array}$ & $\mathbf{2}$ \\
\hline C: imine & $\begin{array}{c}\text { weak analogy } \\
e \text { e }<30 \%\end{array}$ & as in current process & $\begin{array}{c}\text { medium } \\
\text { (good) }\end{array}$ & $\mathbf{3}$ \\
\hline $\begin{array}{l}\text { D: direct } \\
\text { alkylation }\end{array}$ & no precedent & as in current process & $\begin{array}{c}\text { low } \\
\text { (very good) }\end{array}$ & $\mathbf{4}$ \\
\hline
\end{tabular}

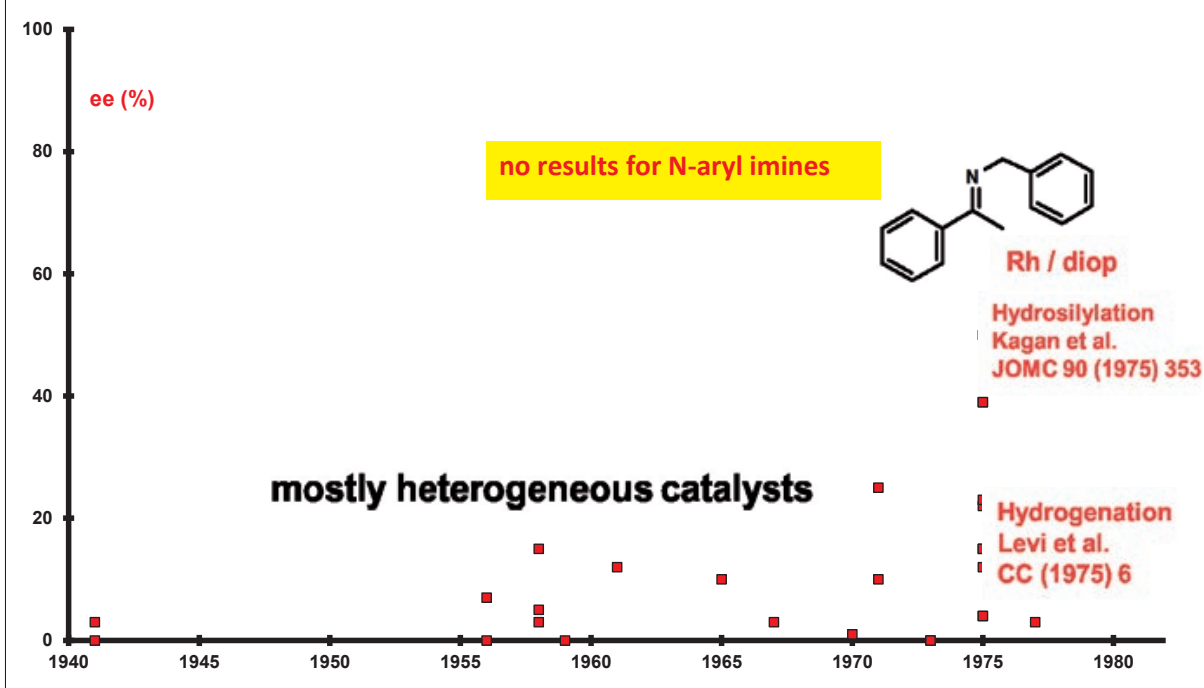

Fig. 20. State of the art of the enantioselective $\mathrm{C}=\mathrm{N}$ reduction in 1980.

\section{The Final Breakthrough with a New Ligand and a Bit of Acid}

As a consequence, a variety of new ligand types were synthesized and tested. The most promising were Josiphos ligands, novel ferrocenyl diphosphines developed by Antonio Togni[44] (Fig. 22). Since the phosphino groups are introduced sequentially in the last two steps, the electronic and steric properties can easily be varied, which is often difficult with other diphosphines. To our delight, several Ir-Josiphos catalysts proved to be very efficient. Most notably, Xyliphos led to an exceptionally active catalyst and, even more important, it did not deactivate!

With Xyliphos as ligand, a screen of solvents and additives as well as an optimization of the reaction conditions were carried out. Hans-Peter Jalett, the experienced chief technician mentioned above, observed again an extraordinary effect: By adding 30\% acetic acid to the reaction mixture in the presence of Ir-Xyliphos and $\mathrm{NBu}_{4} \mathrm{I}$, the maximum rate increased by a factor of five. Even more exciting, the time needed for $100 \%$ conversion was more than 20 times shorter! It turned out that this was not a solvent but a general acid effect and that the same acceleration could be achieved with traces of a strong acid. The reaction rate was approximately proportional to the hydrogen pressure and also increased with temperature. Enantioselectivities decreased from $81 \%$ at $-10{ }^{\circ} \mathrm{C}$ to $76 \%$ at $60{ }^{\circ} \mathrm{C}$ but were not affected by changing the hydrogen pressure.

While these Ir-Xyliphos catalysts surpassed the required catalyst activity and productivity by far, the enantioselectivity just barely met the goal of $80 \% e e$. Therefore, we tried to improve the enantioselectivity by changing both the electronic and steric properties of the Josiphos ligands. As shown in Table 5, this was indeed possible; however, as previously observed with other ligands, any gain in selectivity was offset by a loss in catalyst activity and/or productivity. In the end, Xyliphos was the best compromise for a technical process

\section{Developing a Technical Process}

For this task, a large project team was set up consisting of process and analytical chemists, engineers, as well as specialists in catalysis. While the technical preparation of methoxyacetone and the chloroacetylation step were already established for producing racemic metolachlor, several facets of the new process required considerable development effort.

\section{Optimization of Reaction Medium and} Conditions

After optimization of acid and iodide and reaction conditions, MEA imine could 


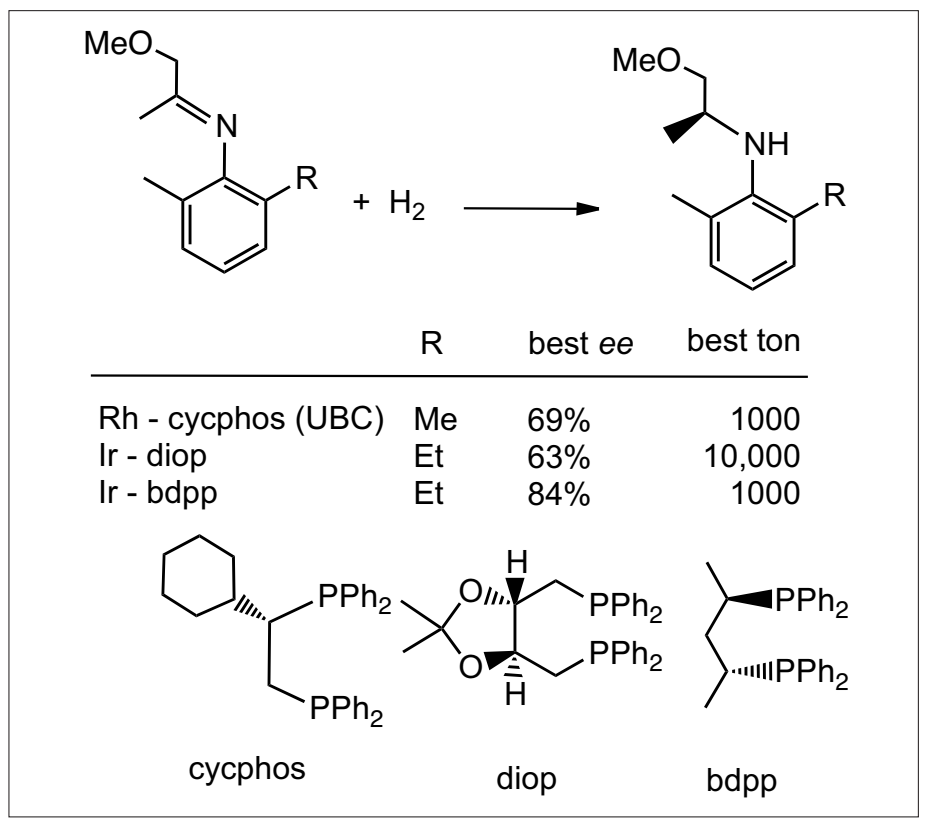

Fig. 21. Rh- and Ircatalyzed hydrogenation of DMA $(R=M e)$ and MEA $(R=E t)$ imine.

be hydrogenated at $80 \mathrm{bar} / 50{ }^{\circ} \mathrm{C}$ with a substrate to catalyst ratio of $>1$ million. Complete conversion was reached within 4 h with an enantioselectivity of 79-80\%, the initial turnover frequency exceeding 1.8 million $\mathrm{h}^{-1}$.

\section{Ligand Synthesis}

Since $(R)$-Ugi amine was not commercially available at the time, a scalable synthesis had to be developed. The chemistry summarized in Figs. 22 and 23 allows for the preparation of a variety of Josiphos ligands with $>99.5 \%$ ee in multi kg quantities. This expertise was decisive when we started our ligand business a few years later.

\section{Choice of Reactor Technology}

Since the catalytic reaction was extraordinarily fast, optimal mass and heat transfer was required and for this purpose, a loop reactor was the best choice. In this technology, the reaction mixture is pumped via a heat exchanger through a nozzle where hydrogen is fed into the reaction solution allowing both very good cooling and mixing (Fig. 24).

The first production batch was successfully run on November 16, 1996 and has been carried out without any major problems on a $>10,000 \mathrm{t} / \mathrm{y}$ scale ever since. ${ }^{[45]}$ The accomplishments of the metolachlor team were recognized by the Swiss Chemical Society with the prestigious Sandmeyer Prize 1999 for achievements in the field of industrial chemistry. On March 23, 1999 the whole development team met a last time, first for the reception of the prize during the spring session of the Swiss Chemical Society and then for a dinner with our partners in the renowned restaurant Schützenhaus to celebrate the occasion.

\section{Some Take Home Lessons}

The metolachlor process is still the largest enantioselective catalytic process and Ir - Xyliphos is the most active and productive catalyst developed to date. There is no

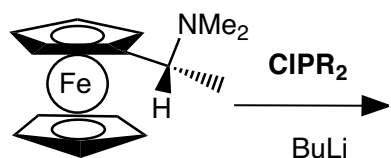

(R)-Ugi amine
Fig. 22. Synthesis of the Josiphos ligand family. doubt that our achievement has laid to rest any doubts about the applicability of chiral homogeneous catalysis for the large scale manufacture of relatively low cost products. We learnt a few lessons which likely are of general interest and which certainly had a strong influence on our strategy for future process development and when we started to build up a commercial ligand portfolio.

Lesson 1: Catalyst activity and productivity is a much more important issue than originally anticipated. Initially, we expected enantioselectivity to be critical; however in reality catalyst activity and productivity provided the greatest challenge in meeting the targets for an economical process. As a consequence, not only ee but also turnover numbers and frequencies values are now routinely monitored even in early stages of any process development.

Lesson 2: Know-how and expertise is decisive. This project caught us quite unprepared. While the Catalysis Section of Ciba-Geigy had a history dating back to the 1940s, its expertise was limited to the application of heterogeneous hydrogenation. We had no experience using chiral complexes and our hydrogenation equipment was not well suited for handling homogeneous catalysts. Thus, at the same time

Table 5. MEA imine hydrogenation with selected Ir-Josiphos catalysts

\begin{tabular}{|c|c|c|c|c|l|}
\hline $\mathrm{R}$ & $\mathrm{R}^{\prime}$ & turnovers & tof $\left(\mathrm{h}^{-1}\right)$ & $e e$ & comments \\
\hline $\mathrm{Ph}$ & $3,5-\mathrm{xylyl}$ & $>1 \mathrm{Mio}$ & $>200,000$ & 79 & production process \\
\hline$p-\mathrm{CF}_{3} \mathrm{C}_{6} \mathrm{H}_{4}$ & $3,5-\mathrm{xylyl}$ & 800 & 400 & 82 & ligand screening \\
\hline $\mathrm{Ph}$ & $4-{ }^{-} \mathrm{Bu}-\mathrm{C}_{6} \mathrm{H}_{4}$ & 5000 & 80 & 87 & low temperature \\
\hline $\mathrm{Ph}$ & $4-\left({ }^{n} \mathrm{Pr}\right)_{2} \mathrm{~N}-3,5-\mathrm{xyl}$ & 100,000 & 28,000 & 83 & optimized conditions \\
\hline
\end{tabular}

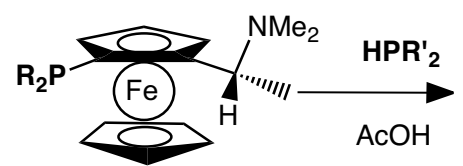

$\left(R, S_{F C}\right)-P P F A$

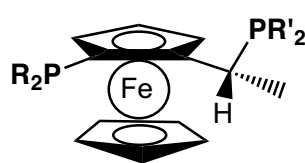

$\left(R, S_{F_{C}}\right)$-Josiphos

Xyliphos: $\mathrm{R}=\mathrm{Ph}, \mathrm{R}^{\prime}=3,5-\mathrm{Xy}$

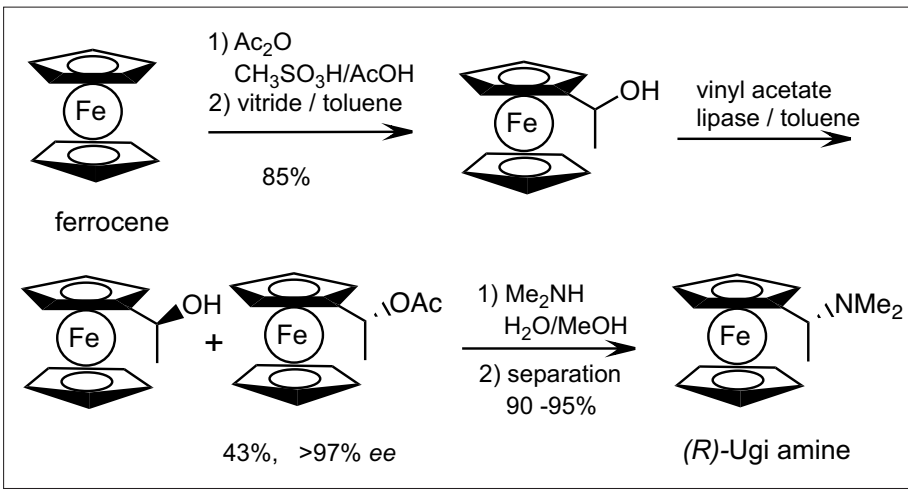

Fig. 23. Technical synthesis of $(R)$-Ugi amine. 


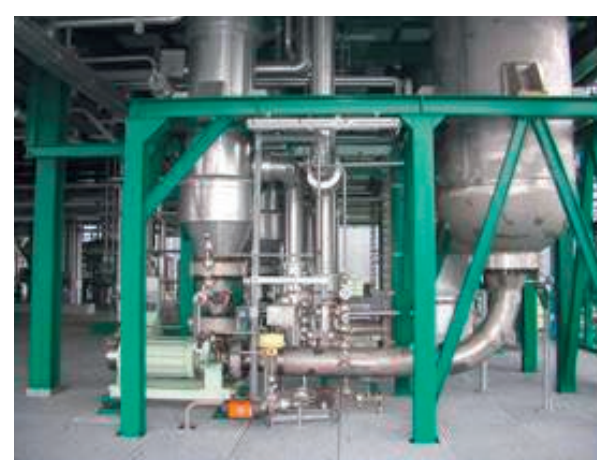

Fig. 24. Lower part of the $10 \mathrm{~m}^{3}$ production loop reactor.

while tackling the $(S)$-metolachlor project, we had to learn the basics of enantioselective catalysis - not a very comfortable position. As a consequence, we initiated a strong research program first for the fast screening of enantioselective catalysts and later in the area of chiral ligand synthesis.

Lesson 3: Availability of chiral ligands. At the beginning of our process development, less than ten chiral diphosphines were commercially available and none in technical quantities. Most of these ligands had $C_{2}$ symmetry and two diphenylphosphino groups, both elements were at the time considered to be essential for good performance in hydrogenation reactions. Josiphos, the first truly modular ligand family, clearly showed that this was not the case. On the contrary, we found that combining $\mathrm{PR}_{2}$ moieties with bulky alkyl groups (even tert-Bu!) with $\mathrm{PAr}_{2}$ groups often led to the most effective ligands. When developing the Josiphos family, we also realized that the ferrocene backbone and its particular chemistry are ideally suited to obtain extraordinarily effective ligands. ${ }^{[46]}$

\section{Building up a Solvias Ligand Portfolio}

Even after the successful completion of the metolachlor project, relatively few chiral ligands were readily available on a commercial scale. We thought that the Josiphos ligands would be a good base for building up a comprehensive ligand portfolio in order to fill this gap. The concept of modularity and the availability of chiral ligands in technical quantities with short lead times were deemed key points for a successful business. ${ }^{47]}$ Thanks to the efforts of Marc Thommen and his colleagues Felix Spindler, Benoît Pugin, Christophe Malan, Pierre Martin, Martin Kesselgruber, Frédéric Naud and Matthias Lotz, the portfolio depicted in Fig. 25 was realized over the years.

Here, I will only briefly describe how this came about because a detailed account has been published. ${ }^{\left[{ }^{39]}\right.}$ It is not by accident that ferrocene-based ligands dominate the portfolio since this ligand backbone has proven to be very efficient allowing for high modularity and, in addition, its chemistry was familiar to our synthetic chemists. After Josiphos, the next addition to our ligand portfolio was Walphos. This ligand family was the result of a co-operative research project with Walter Weissensteiner of the University of Vienna who proposed the synthesis of this class of ferrocene diphosphines. Other groups became also involved in ferrocene-based ligands for hydrogenation. In particular, the Knochel group has achieved remarkable success with Taniaphos and Mandyphos, two ligand families with similar modularity as Josiphos and Walphos but in many cases with complementary performance. ${ }^{[48]} \mathrm{We}$ developed these ligands in collaboration with Umicore (a spin-off from Degussa), who had IP rights to Knochel's patents.

Despite the power of modularity and the versatility of the ferrocene based diphosphines it was appreciated that we had to broaden our ligand portfolio even more. Upon re-analysis of performance gaps of our ligands it became apparent that we were lacking the specific performance of a phospholane-type ligand such as duphos and of an atropisomeric diphosphine-like binap. However, in these areas competition is fierce and it was not easy to devise novel ligands which would be competitive in performance and cost. In collaboration with our former colleague Ulrich Berens from Ciba SC, Butiphane was designed and developed.[49] Unlike duphos, the ligand backbone is not $C_{2}$ symmetrical; rather, it is based on a 5-membered ring backbone which results in a slightly different coordination sphere (sterics and electronics) around the metal when compared to Duphos. The quest for an atropisomeric diphosphine ended in 2006 when Roche agreed to give Solvias a license for the $\mathrm{MeO}-\mathrm{Biphep} \mathrm{ligand} \mathrm{family.}$

With these additions, the ligand portfolio depicted in Fig. 25 fulfills all of our criteria for technical applications concerning tunability, established technical synthesis, easy handling, short term availability for screening, scale-up and manufacturing applications, consistent quality and, last but not least, commercial availability under customized licensing terms.

\section{Epilog}

In the introduction, I stated that catalysis was only a minor concern in the fine chemicals industry when I started my career in 1976. Has this changed in the almost four decades since then? The answer is: YES and NO. NO, because also today most fine chemicals such as pharmaceuticals or agrochemicals are produced using predominantly classical stoichiometric organic chemistry. YES, because today - in contrast to the 1970 s and 1980s - process chemists in chemical development routinely apply selected catalytic methodologies, particularly Pdcatalyzed $\mathrm{C}-\mathrm{C}$ and $\mathrm{C}-\mathrm{N}$ coupling (Suzuki and Buchwald-Hartwig), heterogeneous hydrogenation (nitroarene reduction, debenzylation) and enantioselective reductions (metal complexes, enzymes). Other reaction and catalyst types such as metathesis, (asymmetric) oxidation and condensation reactions are also being used more frequently by industrial chemists, as is organocatalysis. In my opinion, this change in attitude is the result of several factors. Due to the efforts of countless cat-

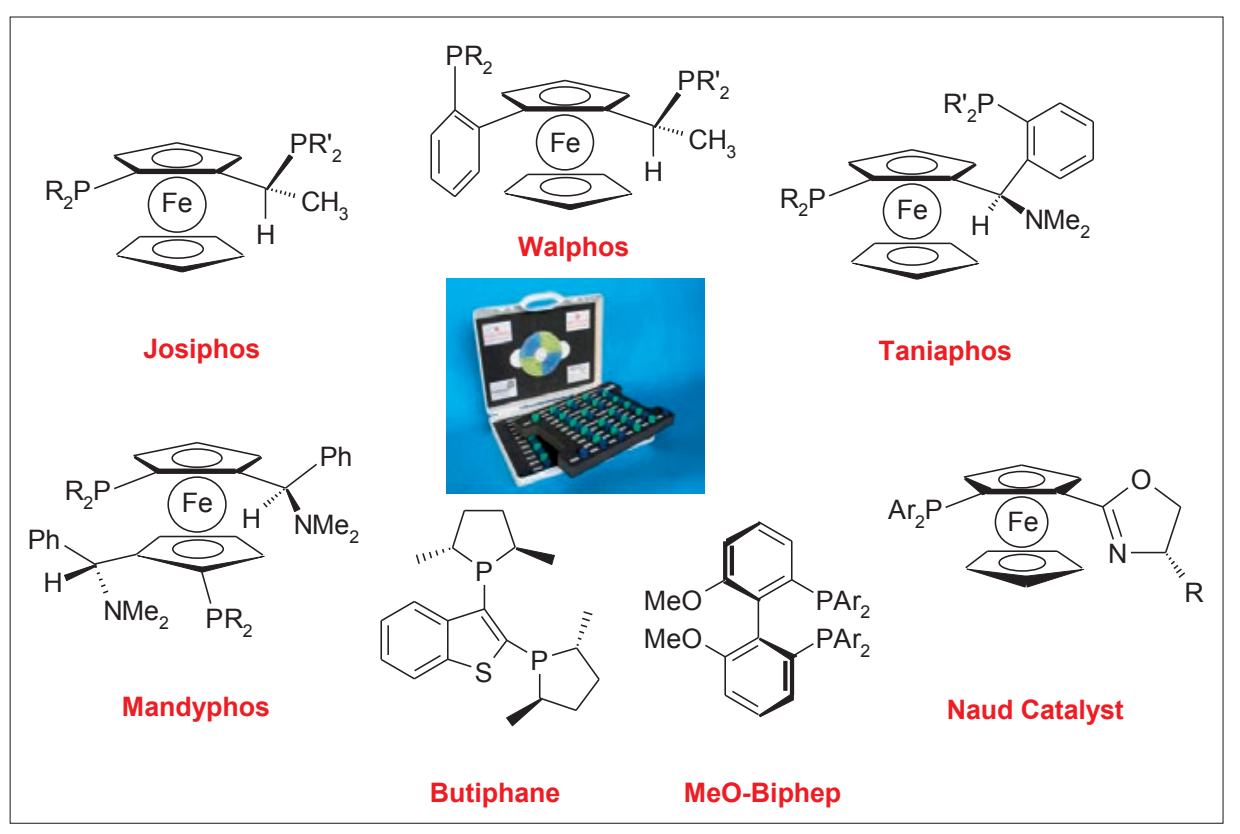

Fig. 25. The Solvias Ligand Portfolio. 
alytic chemists both in industry (such as our group) and academia many catalytic methods have been developed to a degree where they can be applied to multifunctional molecules with good selectivity, are relatively easy to carry out and - last but not least - are cost effective and competitive. Prerequisites for the application of a specific method are that scope and limitations are well known, that other functional groups are well tolerated and that the process chemist is familiar with catalytic reactions. This latter aspect has improved considerably, also because outsourcing to companies with specialized catalytic know-how (such as Solvias) is now widespread - much in contrast to when I started working for Ciba-Geigy when keeping important technology in-house and under control was considered to be very important. Since time for process development is usually quite short (the $(S)$-metolachlor example is certainly the exception and not the rule) it is essential that catalysts (or ligands) are commercially available, both for rapid screening and in later development phases in technical quantities. In this area, Solvias has made important contributions with its chiral ligands for homogeneous hydrogenation (at the moment $>80$ different chiral phosphines) and very active $\mathrm{Pd}$ catalysts and phosphine ligands for $\mathrm{C}-\mathrm{C}$ and $\mathrm{C}-\mathrm{N}$ coupling reactions (at the moment $>15$ ). Success breeds success: It is very likely that the various success stories of the Catalysis group of Ciba-Geigy/Novartis/Solvias have convinced $R \& D$ chemists in other companies that catalytic methods have a very good potential not just for producing large scale bulk chemicals but also for the technical synthesis of the complex molecules encountered in the fine chemicals industry.

Received: May 26, 2015

[1] For a more detailed discussion see a) H. U. Blaser, 'Heterogeneous catalysis for fine chemicals production', Catal. Today 2000, 60 , 161 ; b) H. U. Blaser, 'Enantioselective catalysis in fine chemicals production', Chem. Comm. 2003, 293.

[2] For an overview see D. Reinehr, Pure \& Appl. Chem. 1980, 52, 2417.

[3] R. Bader, P. Baumeister, H. U. Blaser, 'Catalysis at Ciba-Geigy', Chimia 1996, 50, 99.

[4] H. U. Blaser, M. Studer, 'The Spin-off of Scientific Services of Novartis into a New, Independent Technology Company Offering Services to the Pharmaceutical, Chemical and Nutrition Industry', Chimia 1999, 53, 261.
[5] For a detailed description see H. U. Blaser, A Indolese, F. Naud, U. Nettekoven, A. Schnyder, 'Industrial R\&D on Catalytic $\mathrm{C}-\mathrm{C}$ and $\mathrm{C}-\mathrm{N}$ Coupling Reactions: A Personal Account on Goals, Approaches and Results', Adv. Synth. Catal. 2004, 346, 1583. Excerpts from this article are published with the permission of John Wiley and Sons.

[6] a) A. Spencer, J. Organomet. Chem. 1983, 258 , 101; b) A. Spencer, J. Organomet. Chem. 1983, $258,101$.

[7] a) H. U. Blaser, A. Spencer, J. Organomet. Chem. 1982, 233, 267; b) A. Spencer, J. Organomet. Chem. 1983, 247, 117; c) A. Spencer, J. Organomet. Chem. 1982, 240, 209; d) A. Spencer, J. Organomet. Chem. 1984, 265 , 323.

[8] For an overview see a) P. Baumeister, H. U. Blaser, U. Siegrist, M. Studer, Chem. Ind. 1998, 75, 207; b) H. U. Blaser, H. Steiner, M. Studer, 'Selective Catalytic Hydrogenation of Functionalized Nitroarenes: An Update', ChemCatChem 2009, 1, 210.

[9] For a detailed description and references see H. U. Blaser, M. Studer, 'Cinchona Modified Platinum Catalysts: From Ligand Acceleration to Technical Processes', Acc. Chem. Res. 2007, 40, 1348. Excerpts from this article are published with the permission of the American Chemical Society.

[10] J. T. Wehrli, 'Enantioselektive Hydrierung von $\alpha$-Ketoestern mit modifizierten Platin Katalysatoren', $\mathrm{PhD}$ Thesis No. 8833, ETH Zürich, 1989.

[11] E. N. Jacobsen, I. Marko, W. S. Mungall, G. Schröder, K. B. Sharpless, J. Am. Chem. Soc. 1988, 110, 1968.

[12] M. Garland, H. U. Blaser, J. Am. Chem. Soc. 1990, 112, 7048 .

[13] M. Garland, H. U. Blaser, H. P. Jalett, J. Catal. 1993, 144, 569.

[14] H. U. Blaser, H. P. Jalett, M. Garland, M. Studer, H. Thies, A. Wirth-Tijani, J. Catal. 1998, 173, 282.

[15] H. U. Blaser, H. P. Jalett, D. Monti, A. Baiker, J T. Wehrli, Stud. Surf. Sci. Catal. 1991, 67, 147.

[16] T. Buergi, A. Baiker, Acc. Chem. Res. 2004, 37 , 909.

[17] S. Lavoie, M. A. Laliberte, I. Temprano, P. H McBreen, J. Am. Chem. Soc. 2006, 128, 7588.

[18] H. U. Blaser, H. P. Jalett, W. Lottenbach, M. Studer, J. Am. Chem. Soc. 2000, 122, 12675.

[19] M. Schürch, T. Heinz, R. Aeschimann, T Mallat, A. Pfaltz, A. Baiker, J. Catal. 1998, 173 187 and references therein.

[20] C. Exner, 'Enantioselektive Hydrierungen mit heterogenen Platin-Katalysatoren Synthese und systematischer Vergleich chiraler Modifikatoren', Thesis, University of Basel, 2002.

[21] C. Exner, A. Pfaltz, M. Studer, H. U. Blaser, Adv. Synth. Catal. 2003, 345, 1253.

[22] H. U. Blaser, H. P. Jalett, Stud. Surf. Sci. Catal. 1993, 78, 139

[23] M. Studer, S. Burkhardt, A. F. Indolese, H. U. Blaser, Chem. Commun. 2000, 1327

[24] a) N. Künzle, R. Hess, T. Mallat, A. Baiker, J. Catal. 1999, 186, 239; b) N. Künzle, A. Szabo, M. Schürch, G. Wang, T. Mallat, A. Baiker, Chem. Commun. 1998, 1377.

[25] M. Studer, S. Burkhardt, H. U. Blaser, Chem. Commun. 1999, 1727.
[26] M. Studer, H. U. Blaser, S. Burkhardt, $A d v$. Synth. Catal. 2002, 344, 511.

[27] M. Studer, H. U. Blaser, V. Okafor, Chem. Commun. 1998, 1053.

[28] M. von Arx, T. Bürgi, T. Mallat, A. Baiker, Chem. Eur. J. 2002, 8, 1430, and references therein.

[29] H. U. Blaser, H. P. Jalett, J. Wiehl, J. Mol. Catal. 1991, 68, 215.

[30] H. U. Blaser, H. P. Jalett F. Spindler, J. Mol. Catal. A: Chemical 1996, 107, 85.

[31] G. Sedelmeier, H. U. Blaser, H. P. Jalett; EP 206'993, 1986 (CAN 107, 77434).

[32] P. Herold, A. F. Indolese, M. Studer, H. P. Jalett, H. U. Blaser, Tetrahedron 2000, 56, 6497.

[33] For a contemporary review on homogeneous catalysis see H. B. Kagan, J. C. Fiaud, Topics in Stereochem. 1978, 10, 196.

[34] W. Bergstein, A. Kleemann, J. Martens, Synthesis 1981, 76

[35] V. Caplar, G. Comisso, V. Sunjic, Synthesis 1981, 85

[36] G. M. Ramos Tombo, H. U. Blaser in 'Pesticide Chemistry and Bioscience', Eds. G. T. Brooks, T. R. Roberts, Royal Society of Chemistry: Cambridge, 1999, p. 33, and references therein.

[37] H. Moser, G. Rihs, H. P. Sauter, Z. Naturforsch. 1982, 37b, 451 .

[38] H. U. Blaser, 'The Chiral Switch of (S)Metolachlor: A Personal Account of an Industrial Odyssey in Asymmetric Catalysis', Adv. Synth. Catal. 2002, 344, 17. Excerpts from this article are published with the permission of John Wiley and Sons.

[39] H. U. Blaser, B. Pugin, F. Spindler, M Thommen, 'From a Chiral Switch to a Ligand Portfolio for Asymmetric Catalysis', Acc. Chem. Res. 2007, 40, 1240. Excerpts from this article are published with the permission of the American Chemical Society.

[40] B. D. Vineyard, W. S. Knowles, M. J. Sabacky, G. L. Bachman, D. J. Weinkauff, J. Am. Chem. Soc. 1977, 99, 5946.

[41] W. R. Cullen, M. D. Fryzuk, B. R. James, J. P. Kutney, G.-J. Kang, G. Herb, I. S. Thorburn, R. Spogliarich, J. Mol. Catal. 1990, 62, 243.

[42] R. H. Crabtree, H. Felkin, T. Fillebeen-Khan, G. E. Morris, J. Organometal. Chem. 1979, 168, 183.

[43] F. Spindler, B. Pugin, H. U. Blaser, Angew. Chem. Int. Ed. 1990, 29, 558.

[44] A. Togni, Chimia 1996, 50, 86.

[45] R. Hofer, 'In Kaisten, Syngenta operates the world's largest plant in which an enantioselective catalytic hydrogenation is performed. How did this come about?' Chimia 2004, 59, 10.

[46] H. U. Blaser, W. Brieden, B. Pugin, F. Spindler, M. Studer, A. Togni, 'Solvias Josiphos Ligands: From Discovery to Technical Application', Topics in Catal. 2002, 19, 3.

[47] H. U. Blaser, M. Thommen, 'Industrial Aspects in Trivalent Phosphorus Compounds in Asymmetric Catalysis: Synthesis and Applications', Ed. A. Börner, Wiley-VCH, 2008, p. 1457.

[48] F. Spindler, C. Malan, M. Lotz, M. Kesselgruber, U. Pittelkow, A. Rivas-Nass, O. Briel, H. U. Blaser, 'Modular chiral ligands: the profiling of the Mandyphos and Taniaphos ligand families', Tetrahedron: Asymmetry 2004, 15, 2299.

[49] U. Berens, U. Englert, S. Geyser, J. Runsink, A. Salzer, Eur. J. Org. Chem. 2006, 2100. 